\title{
Rules versus Standards: An Economic Analysis
}

\section{Citation}

Louis Kaplow, Rules versus Standards: An Economic Analysis, 42 Duke L.J. 557 (1992).

\section{Published Version}

doi: $10.2307 / 1372840$

\section{Permanent link}

http://nrs.harvard.edu/urn-3:HUL.InstRepos:10611784

\section{Terms of Use}

This article was downloaded from Harvard University's DASH repository, and is made available under the terms and conditions applicable to Other Posted Material, as set forth at http:// nrs.harvard.edu/urn-3:HUL.InstRepos:dash.current.terms-of-use\#LAA

\section{Share Your Story}

The Harvard community has made this article openly available.

Please share how this access benefits you. Submit a story.

\section{Accessibility}




\section{Duke University School of Law}

Rules versus Standards: An Economic Analysis

Author(s): Louis Kaplow

Source: Duke Law Journal, Vol. 42, No. 3 (Dec., 1992), pp. 557-629

Published by: Duke University School of Law

Stable URL: http://www.jstor.org/stable/1372840

Accessed: 22/03/2010 10:42

Your use of the JSTOR archive indicates your acceptance of JSTOR's Terms and Conditions of Use, available at http://www.jstor.org/page/info/about/policies/terms.jsp. JSTOR's Terms and Conditions of Use provides, in part, that unless you have obtained prior permission, you may not download an entire issue of a journal or multiple copies of articles, and you may use content in the JSTOR archive only for your personal, non-commercial use.

Please contact the publisher regarding any further use of this work. Publisher contact information may be obtained at http://www.jstor.org/action/showPublisher?publisherCode=dusl.

Each copy of any part of a JSTOR transmission must contain the same copyright notice that appears on the screen or printed page of such transmission.

JSTOR is a not-for-profit service that helps scholars, researchers, and students discover, use, and build upon a wide range of content in a trusted digital archive. We use information technology and tools to increase productivity and facilitate new forms of scholarship. For more information about JSTOR, please contact support@jstor.org.

Duke University School of Law is collaborating with JSTOR to digitize, preserve and extend access to Duke Law Journal. 


\title{
RULES VERSUS STANDARDS: AN ECONOMIC ANALYSIS
}

\author{
LOUIS KAPLOW $\dagger$
}

This Article offers an economic analysis of the extent to which legal commands should be promulgated as rules or standards. Two dimensions of the problem are emphasized. First, the choice between rules and standards affects costs: Rules typically are more costly than standards to create, whereas standards tend to be more costly for individuals to interpret when deciding how to act and for an adjudicator to apply to past conduct. Second, when individuals can determine the application of rules to their contemplated acts more cheaply, conduct is more likely to reflect the content of previously promulgated rules than of standards that will be given content only after individuals act. The Article considers how these factors influence the manner in which rules and standards should be designed, and explores the circumstances in which rules or standards are likely to be preferable. The Article also addresses the level of detail with which laws should be formulated and applied, emphasizing how this question concerning the laws' relative simplicity or complexity can be distinguished from that of whether laws are given content ex ante (rules) or ex post (standards). In so doing, it illuminates concerns about the over- and underinclusiveness of rules relative to standards.

$\dagger$ Professor, Harvard Law School and Research Associate, National Bureau of Economic Research. I am grateful for comments from Lucian Bebchuk, James Boyle, Scott Brewer, David Charny, Erwin Chemerinsky, Stephen Choi, Richard Fallon, Marcel Kahan, Jeremy Paul, Richard Posner, Frederick Schauer, Steven Shavell, and participants in workshops at the University of Chicago, University of Connecticut, and Harvard University law schools. 


\section{TABLE OF CONTENTS}

INTRODUCTION . . . . . . . . . . . . . . . . . . . . . . 559

I. EX ANTE VERSUS EX POST CREATION OF

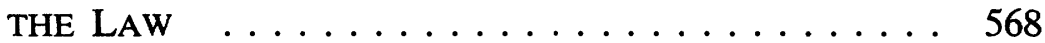

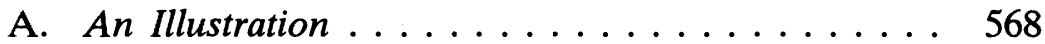

1. Law Promulgation . . . . . . . . . . . . . . 568

2. Choices of Individuals . . . . . . . . . . 569

3. Law Enforcement . . . . . . . . . . . 570

B. Analysis ...................... 571

1. Individuals Do Not Become Informed Either Under a Rule or Under a Standard . . . . . . . 572

2. Individuals Become Informed both Under a Rule and Under a Standard . . . . . . . . . . 574

3. Individuals Become Informed Under a Rule but Not Under a Standard . . . . . . . . . . . 575

C. Precedent ................... 577

D. The Degree of Effort Devoted to Rule Creation, Legal Advice, and Enforcement . . . . . . . . 579

1. Law Promulgation . . . . . . . . . . . . . . 579

2. Choices of Individuals . . . . . . . . . 580

3. Law Enforcement . . . . . . . . . . . . . 581

E. Creation of the Law as Information Acquisition and Dissemination ................ 585

II. RULES VERSUS STANDARDS AND COMPLEXITY:

ON OVER- AND UNDERINCLUSIVENESS . . . . . . . 586

A. Distinguishing Complexity from the Choice Between Rules and Standards: Definitions . . . . 586

B. Distinguishing Complexity from the Choice Between Rules and Standards: Implications . . . . 588

C. Analyzing the Problem of Over- and Underinclusiveness . . . . . . . . . . . . . . 590

D. Are Standards Systematically More Complex in Application than Rules? . . . . . . . . . . . 593

III. EXTENSIONS . . . . . . . . . . . . . . . . 596

A. The Accessibility of Rules and Standards . . . . . 596

B. The Difficulty of Formulating Some Laws as Rules

C. The Private Versus Social Value of Legal Advice . . . . . . . . . . . . . . . . . . 602

D. Risk Aversion . . . . . . . . . . . . . . 605 
E. Objectives of the Law Other than Deterrence . . . 606 IV. FURTHER CONSIDERATIONS . . . . . . . . . 608

A. Promulgation and Enforcement of Law by

Different Government Institutions . . . . . . . . 608

B. Precedent and Predictability ............. 611

1. The Time Taken to Promulgate Precedents .. 612

2. Predictability Without Precedent ......... 614

3. Predictability Without Formally Articulated Rules ... . . . . . . . . . . . . . . 615

C. Changing Rules and Standards over Time ..... 616

D. Laws Regarding Form and Background Laws . . 618

E. Lawyers' Interest in How the Law Is

Formulated . . . . . . . . . . . 620

V. CONCLUSION .................. 621

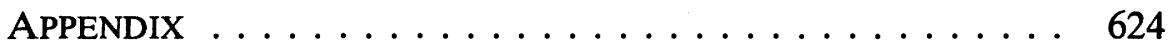

\section{INTRODUCTION}

This Article offers an economic analysis of the extent to which legal commands should be promulgated as rules or standards, a question that has received substantial attention from legal commentators. ${ }^{1}$ Arguments about and definitions of rules and standards commonly emphasize the distinction between whether the law is given content ex ante or ex post. ${ }^{2}$ For example, a rule

1. The two most substantial attempts to analyze the choice from an economic perspective $: \rightarrow$ Colin S. Diver, The Optimal Precision of Administrative Rules, 93 YALE L.J. 65 (1983), a $\rightarrow$ Isaac Ehrlich \& Richard A. Posner, An Economic Analysis of Legal Rulemaking, 3 J. LEgAl STUD. 257 (1974). See also KENNETH C. DAVIS, DisCRETIONARY JUSTICE: A PRELIMINARY INQUIRY (1969); Anthony I. Ogus, Quantitative Rules and Judicial Decision Making, in THE ECONOMIC APPROACH TO LAW 210 (Paul Burrows \& Cento G. Veljanovski eds., 1981). Other prominent discussions, often emphasizing definitions and jurisprudential concerns, include P.S. ATIYAH \& ROBERT S. SUMMERS, FORM AND SUBSTANCE IN ANGlO-AMERICAN LAW: A COMPARATIVE STUDY IN LEgAl REASONING, LEgAL THEORY AND LEgAL INSTITUTIONS (1987); H.L.A. HART, THE CONCEPT OF LAW 126-31 (1961); HENRY M. HART \& AlberT M. SACKS, THE LEgal Process 155-58 (tent. ed. 1958); MARK KelMaN, A GuIDE TO CRITICAL Legal STUdies 15-63 (1987); Richard A. Posner, The Problems of Jurisprudence 42-53 (1990); Roscoe Pound, AN INTROduction to THE PHILOSOPHY OF LAW 115-23 (1922); FredERICK Schauer, Playing by the Rules: A Philosophical Examination of Rule-Based DECISIONMAKING IN LAW AND IN LIFE (1991); ROBERTO UNGER, KNOWLEDGE AND Politics 88-100 (197 $\rightarrow$ Ronald M. Dworkin, The Model of Rules, 35 U. CHI. L. REV. 14, 22-29 (1967); Duncan Kennedy, Form and Substance in Private Law Adjudication, 89 HARV. L. REV. 1685 (1976); Roscoe Pound, Hierarchy of Sources and Forms in Different Systems of Law, 7 TUL. L. REV. 475, 482-87 (1933).

2. See, e.g., HART, supra note 1, at 127-29; HART \& SACKS, supra note 1, at 157 
may entail an advance determination of what conduct is permissible, leaving only factual issues for the adjudicator. (A rule might prohibit "driving in excess of 55 miles per hour on expressways.") A standard may entail leaving both specification of what conduct is permissible and factual issues for the adjudicator. (A standard might prohibit "driving at an excessive speed on expressways." $)$ This Article will adopt such a definition, in which the only distinction between rules and standards is the extent to which efforts to give content to the law are undertaken before or after individuals act. ${ }^{4}$ Other properties of rules and standards, including many emphasized in the jurisprudential literature, will be noted only in passing. ${ }^{5}$

("The wise draftsman . . . asks himself, how many of the details of this settlement ought to be postponed to another day, when the decisions can be more wisely and efficiently and perhaps more readily made?"). There is, however, substantial variation in the use of terminology and in the content of definitions, sometimes even by a single author. The choice of "rules" and "standards" as terms may contribute to the confusion. Outside the debate over formulation of the law, the terms are often used interchangeably. Dictionaries include as common meanings of "rule," "a standard of judgment" and "a regulating principle." WEBSTER's NEW COLlEGIATE DiCTIONARY 1012 (1977). Common meanings for "standard" include "something set up and established by authority as a rule for the measure of quantity, weight, extent, value, or quality." Id. at 1133 . "Criterion" is listed as a synonym for both terms. Thus, one is not surprised when Ronald Dworkin uses "standards" to encompass both concepts as defined here, and uses "principles" in place of the more conventional "standards." $: \rightarrow$ Dworkin, supra note 1 , at 22-25. (I refer here to Dworkin's discussion of the rules and standards question, as distinct from much of his other jurisprudential work in which his use of the term "principles" plays a different role.) In this Article, I will attempt to minimize confusion by using the term "law" (and various derivatives) to refer generically to legal commands.

3. This example would not differ from that of the rule if all adjudicators held the view that an "excessive speed on expressways" was any speed "in excess of 55 miles per hour." Yet for purposes of this illustration, assume that the inquiry into "excessive speed" is relatively open-ended and requires real effort on the part of the decisionmaker in many cases. See infra Part II (a seemingly open-ended standard might be applied in a more straightforward fashion); Section III(B) (whether a law is a standard is determined by how it is understood rather than by the language in which it is formulated); subsection $\operatorname{IV}(B)(3)$ (government undertakes a study, publishing the results but not embodying them in a regulation).

4. In particular, as explored in Part II, this Article distinguishes the question of when a legal command is given content from how much detail is used in differentiating cases. Often, this latter dimension is expressly included. See, e.g., Frederick Schauer, Rules and the Rule of Law, 14 HARV. J.L. \& PUB. POL'Y 645, 650-51 (1991) ("Where the categories of decision are both large and opaque, the dimension of ruleness is greatest, and where the categories are narrow and more transparent to background justifications, the constraints of ruleness are minimized."). But see Ruth Gavison, Comment: Legal Theory and the Role of Rules, 14 HARv. J.L. \& PUB. POL'Y 727, 747-48 (1991) (suggesting that only the strength of entrenchment and not breadth be incorporated in the concept of ruleness).

5. This Article will not address such issues as whether binding rules are possible, 
The language of this Article will follow the common practice of referring to rules and standards as if one were comparing pure types, even though legal commands mix the two in varying degrees. ${ }^{6}$ One can think of the choice between rules and standards

given the limits of language, or whether rules can be interpreted independently of their underlying justifications (which may be standards). See generally JOSEPH RAZ, PRACTICAL REASON AND NORMS 49-84 (1990); SCHAUER, supra note 1. Rather, the Article adopts the perspective-which I believe is amply defended in the relevant literature (and which one might have thought needed no defense)-that it often is meaningful to say that a law has been given some content ex ante, which the adjudicator should, could, and would take into account. See, e.g., Frederick Schauer, Rules and the Rule-Following Argument, 3 CAN. J.L. \& JURISPRUDENCE 187 (1990) [hereinafter Schauer, Rules]. Moreover, as many of the examples (such as the Internal Revenue Code and OSHA regulations) suggest, the realm in which this perspective is applicable to a great extent and is practically important is immense. See also the examples $t] \rightarrow$ Diver, supra note 1 , explores in depth. (Perhaps it is the refusal to consider routine applications of the law that leads some, such as Pierre Schlag, Rules and Standards, 33 UCLA L. REV. 379, 400-18 (1985), to believe that considering the virtues and vices of rules and standards is a meaningless endeavor.) Sections II(A) and IV(A) touch on these jurisprudential concerns.

A concern related to whether rules can be binding is whether there is any content to a rule as long as a standard can trump the rule. When standards can be employed ex post to trump rules, the value of rules might be significantly eroded to the extent their purpose was primarily to constrain adjudicators' discretion for fear of abuse. See infra note 142 and accompanying text. But to the extent that adjudicators are faithful executors of legal commands, they would choose to use ex ante determinations to an appropriate extent. (In fact, pressures of time and cost would, as a practical matter, give them a great-perhaps an excessive-incentive to do so.) The focus in this Article is on the value of $e x$ ante determinations, not on whether such determinations should be or can be made absolutely binding. See, e.g., infra subsection IV(B)(3). The analysis emphasizes how laws-both rules and standards-will actually be applied and the relative difficulty of predicting their application. Thus, a law is "rule-like" if it in fact facilitates resolution of cases $e x$ post and makes prediction easier ex ante, even if it expressly allows the adjudicator to create exceptions ex post (for example, with the suggestion that "these rules apply unless some other result is appropriate in light of the considerations motivating formulation of this law"). See SCHAUER, supra note 1, at 98-99 (even if the adjudicator is explicitly empowered to ignore the rule, it may produce many virtues of rules, although not that of allocating power to one other than the adjudicator). For discussions of the jurisprudence of presumptive rules, see, e.g., RAZ, supra, at 59-62; SCHAUER, supra note 1, at 108-11 (even "mere" rules of thumb may provide guidance); Schauer, supra note 4. On the related question of exceptions to rules, see Frederick Schauer, Exceptions, 58 U. CHI. L. REV. 871, 893-98 (1991).

The view that aspects of rules can usefully be analyzed while setting aside related issues of legal theory is not novel. See, e.g., Gavison, supra note 4, at 730, 768-70 (concluding that "we should discuss the role of rules in law on its own merits, without trying to implicate general legal theory in the discussion," but noting similarities in scholars' use of theories of law and formal attributes of decisionmaking). In part, the separation is appropriate because many properties of rules (and standards), including much of what is explored in this Article, are not unique to legal rules, as distinct from rules followed in other realms of life. See, e.g., SCHAUER, supra note 1; Schauer, Precedent, 39 STAN. L. REV. 571, 572, 602-03 (1987) [hereinafter Schauer, Precedent].

6. For example, a rule may determine which of two standards applies, or vice versa 
as involving the extent to which a given aspect of a legal command should be resolved in advance or left to an enforcement authority to consider. Thus, advance determination of the appropriate speed on expressways under normal conditions, or even of the criteria that will be relevant in adjudicating reasonable speed (safety and the value of time, but not the brand of automobile or the particular driver's skill), are "rule-like" when compared to asking an adjudicator to attach whatever legal consequence seems appropriate in light of whatever norms and facts seem relevant. ${ }^{7}$ Yet the same advance determination would be "standard-like" when compared to a precise advance determination of what constitutes normal conditions and what constitutes reasonable speed under various exceptional circumstances.

The analysis in Part I examines the relative desirability of $e x$ ante versus ex post creation of the law in terms of legal costs and the extent to which individuals' behavior conforms to the law. ${ }^{8}$ It focuses on an intentionally simple example-made more complex later-that is used to identify fundamental differences between rules and standards. The example has three stages: (1) A law is promulgated, either as a rule or as a standard. (2) Individuals decide how to act. Being imperfectly informed of the law's commands, they either act based on their best guess of the law, or they acquire legal advice, which allows them to act with knowledge of a rule or a prediction of the application of a standard. (3) After individuals act, an adjudicator determines how the governing law applies. Rules are more costly to promulgate than standards because rules involve advance determinations of the law's content, whereas standards are more costly for legal advisors to

(as when two rules arguably govern and some principle must be invoked to choose between the rules). Even focusing on a single step in reaching a legal conclusion, a particular law will have qualities of rules and of standards, with competing formulations differing in the degree to which they are rule- or standard-like. See also infra note 83. An important mixed type is the presumptive rule, in which a rule applies unless there appears to be sufficient reason not to apply it (and in which the decisionmaker does not first conduct a full inquiry to determine whether applying the rule is correct). See Gavison, supra note 4, at 750-52; supra note 5 .

7. Cf. Thomas C. Arthur, Workable Antitrust Law: The Statutory Approach to Antitrust, 62 TUL. L. REV. 1163, 1225-28 (1988) (rejecting sharp dichotomy between rules and standards, instead advocating a middle position in which the legislature identifies goals and offers examples as guides for courts).

8. The analysis emphasizes how laws affect ex ante behavior rather than other goals, some of which are noted in Section III(E). 
predict or enforcement authorities to apply because they require later determinations of the law's content.

To illustrate the analysis, consider the problem of regulating the disposal of hazardous substances. For chemicals used frequently in settings with common characteristics-such as dry cleaning and automotive fluids-a rule will tend to be desirable. If there will be many enforcement actions, the added cost from having resolved the issue on a wholesale basis at the promulgation stage will be outweighed by the benefit of having avoided additional costs repeatedly incurred in giving content to a standard on a retail basis. ${ }^{9}$ Moreover, with regard to the countless acts of individuals subject to these laws, a rule will tend to be better as well. Because learning about a rule is cheaper, individuals may spend less in learning about the law, and may be better guided by a rule since the law's content can be more readily ascertained.

Contrast this result to that in the case of chemicals used rarely, and in settings that vary substantially. Designing a rule that accounts for every relevant contingency would be wasteful, as most would never arise. Although it might be more difficult and costly for an individual and an enforcement authority to apply a standard in a particular instance, such an application need be made only if its unique set of circumstances actually arises. Thus when frequency is low, a standard tends to be preferable.

Two features of this example are worth highlighting. First, the frequency of individual behavior and of adjudication is of central importance. Note in this regard that a law may still govern much behavior even though adjudications-which receive more emphasis in legal commentary-are rare, whether because most acts do not give rise to a lawsuit or because most cases are settled..$^{10}$ Laws in which the frequency of application in recurring fact scenarios is

9. Thus, when discussing presumptive rules, Gavison notes that requiring the decisionmaker to examine all relevant factors to determine whether a rule should apply would not make all cases difficult to decide but would "make all cases time-consuming, in ways that are extremely wasteful." Gavison, supra note 4, at 750 ; see HENRY J. FrIENDly, THE FEDERAl AdMINISTRATIVE AgENCIES: THE NEED FOR BETTER DEFINITION OF STANDARDS 24 (1962); RAZ, supra note 5, at 59.60; SCHAUER, supra note 1, at 145-49 \& n.14; $c f$. RICHARD A. POSNER, ECONOMIC ANAlYSIS OF LAW $\S 20.4$, at 547-48 (4th ed. 1992) (similar effect of precedent treated as a rule by subsequent decisionmakers); Schauer, Precedent, supra note 5, at 599 (same).

10. Isaac Ehrlich and Richard Posner have noted that costs of legal advice at the consultation stage may be greater than for advice in litigati $\rightarrow$ Ehrlich \& Posner, supra note 1 , at 270 . 
high include many traffic laws, aspects of the law of damages (how to value disability, loss of life, or lost profits), regulations governing health and safety, and provisions of the federal income tax (some of which apply to millions of individuals and billions of transactions). In contrast, some laws govern more heterogeneous behavior, in which each relevant type of act may be rare. ${ }^{11}$ For example, the law of negligence applies to a wide array of complex accident scenarios, many of which are materially different from each other and, when considered in isolation, are unlikely to occur. ${ }^{12}$

Second, the advantage of rules at the stage involving individuals' behavior depends on whether individuals choose to acquire legal advice before they act. If the benefits of learning the law's content are substantial and the cost (whether of hiring legal experts or learning more on one's own) is not too great, individuals' behavior under both rules and standards will tend to conform to the law's commands. The advantage of rules in this case would be that the cost of learning the law is reduced. If, however, the cost of predicting standards is high, individuals will not choose to become as well informed about how standards would apply to their behavior. The advantage of rules in this case would be improved legal compliance. Thus, even if an enforcement authority were to give the same content (or "better" content) to a standard as might have been included in a rule, the rule might induce behavior that is more in accord with underlying norms.

After developing these ideas, the framework is extended in two ways. First, the analysis is reconsidered in light of the possibility that a standard might be converted into a rule through the creation of a precedent. Second, an inquiry is made into how much effort should and would be invested in promulgating and applying laws. It is noted, for example, that more should be spent on

11. Heterogeneity is emphasized because acts are only frequent in the relevant sense if the acts have enough in common that they should be treated in the same manner. Thus, negligence cases are frequent, although many types of negligence cases are not. See infra Section III(B); cf. Werner Z. Hirsch, Reducing Law's Uncertainty and Complexity, 21 UCLA L. REV. 1233, 1240-41 (1974) (discussing frequency versus heterogeneity in determining whether laws should be more precise so as to avoid uncertainty).

12. Roscoe Pound has stated that "no two cases of negligence have been alike or ever will be alike." Pound, supra note 1 , at 142 . It is less obvious whether the differences are typically of sufficient importance to justify an independent inquiry in each case or whether juries in fact respond to all conceivable subtle differences, issues explored in Part II. 
determining the appropriate resolution of issues when a rule is designed once for many cases than when applying a standard (adjudication) or predicting the application of a standard (legal advice) in a single case. Finally, Part I concludes by observing that the problem of choosing between rules and standards can be viewed as one concerning how the government should acquire and disseminate information about the appropriate content of the law.

Part II seeks to illuminate the intersection between the debate over rules and standards (ex ante versus ex post creation of the law) and the debate over the appropriate degree of detail in legal commands. The focus is on the familiar suggestion that rules tend to be over- and underinclusive relative to standards. ${ }^{13}$ This Part indicates that the suggestion is misleading because typically it implicitly compares a complex standard and a relatively simple rule, whereas both rules and standards can in fact be quite simple or highly detailed in their operation.

For rules, the potential variation in complexity is familiar, even if often ignored. A motor vehicle code could specify a single speed limit, a handful (one each for expressways, city streets, and alleys), or a plethora (identifying different types of roads, vehicles, weather conditions, traffic densities, and driver characteristics). For standards, this point has two important dimensions. Standards may admit few or many considerations in determining their application. A standard that one not drive at an excessive speed may allow only time and safety considerations or may also permit energy conservation considerations; it may deem relevant only road conditions or may also take into account vehicle types. There is, however, another important dimension that is commonly overlooked when analyzing standards: the level of detail actually employed by

13. See, $e \rightarrow$ Ehrlich \& Posner, supra note 1, at 268-70; Kennedy, supra note 1 , at $1689,16 \rightarrow$ William H. Simon, Legality, Bureaucracy, and Class in the Welfare System, 92 YALE L.J. 1198, 1202, 1227 (1983). Coleman, in contrast, emphasizes that "rules are necessarily under- and over-inclusive with respect to the sets of reasons that support or ground them" (instead of in comparison to standards). Jules L. Coleman, Rules and Social Facts, 14 HARV. J. L. \& PUB. POL'Y 703, 710 (1991); see SCHAUER, supra note 1, at 31-34, 50. Schauer describes rules as "entrenched generalizations likely to be under- and over-inclusive in particular cases," in contrast to "particularistic decisionmaking, which aims to optimize for each case and treats normative generalizations as only temporary and transparent approximations." Schauer, supra note 4, at 646; see id. at 648-49. As will be discussed further in Section I(D) and Part II, this sort of comparison, while not inherently misleading, is often understood in a manner that provides an inaccurate picture when considering how systems of rules and standards should or do operate. 
the adjudicator. A standard that one not drive at excessive speed might well permit consideration of dozens of factors. But if ninetynine out of a hundred juries make their decisions based on the same two or three factors, although the other factors are relevant in principle, the de facto standard might usefully be described as a rather simple one. ${ }^{14}$

Thus, there are simple and complex rules as well as simple and complex standards. ${ }^{15}$ Moreover, as a matter of legal practice, it is not always the case that rule systems are simple compared to the standards that could be adopted in their place. Consider the federal income tax. It hardly seems plausible that a standard requiring individuals to pay "their appropriate share of the federal government's revenue needs," applied case by case, ${ }^{16}$ would generate a more detailed law-one that took into account more factors, in more intricate ways - than the one embodied in the Internal Revenue Code and its accompanying regulations.

The conceptual distinction between the questions of how complex a law should be and whether any aspect of its detail is best determined ex ante or ex post has practical importance. For example, a complex standard might be preferred to a simple rule because of its complexity or because of the advantages of ex post formulation, or both. As a result, in some instances in which the complex standard is superior, it may be that complexity is better than simplicity, but a rule-a complex rule-would be preferable

14. $: \rightarrow$ Stephen G. Gilles, Rule-Based Negligence and the Regulation of Activity Lev$e l s, 21$ J. LEGAL STUD. 319, 321-27 (1992) (emphasizing rule-like elements of negligence and standard-like elements of strict liability). Juries may adopt a simple approach because the factors they can readily understand or that appear most salient are few in number. Alternatively, jury instructions may narrow their focus, see, e.g., JOHN DICKINSON, ADMINISTRATIVE JUSTICE AND THE SUPREMACY OF LAW IN THE UNITED STATES 143 (1927) (giving examples involving notice of dishonor of negotiable instruments and due care in tort law), although in this case the standard may have been transformed into a rule to some extent.

15. Colin Diver offers an example with three formulations for a law determining who may pilot commercial aircraft: (1) No one over age 60 ; (2) No one who poses an unreasonable risk of accident; (3) No one who falls in any of a number of categories detailing combinations of values of variables that bear on accident risk. $\rightarrow$ Diver, supra note 1 , at 69. In this example, (1) is a simple rule and (3) a complex rule. The standard is (2), which on its face appears complex, in that in principle it admits any consideration. Diver then notes the possibility that all those applying (2) understand it to mean anyone over 60 , see id., which would be a simple de facto standard.

16. And without the creation of precedents that would make the standard more rulelike. See infra Section I(C). 
to a standard; or, it may be that a standard is better than a rule, but a simple standard would be preferable to a complex one. ${ }^{17}$ For example, a standard (implicitly complex) that one dispose of toxic substances "appropriately" may be preferable to a rule that simply prohibits the dumping of petroleum byproducts into bodies of water. But, at least for substances frequently used in common settings-such as dry cleaning and automotive fluids-a complex rule detailing the appropriate manner of disposal for different substances may be even better. Part II discusses briefly the sort of analysis that is pertinent to a determination of the appropriate level of detail (for example, the extent to which different substances and contexts should be distinguished), noting how it differs from that in Part I (which concerns whether the appropriate manner of disposal should be determined in advance, or only after individuals act, in an adjudication).

Part III extends the framework in a number of ways. First, this Part considers the possibility that standards are more accessible to actors than rules are, contrary to the suggestion in Part I. Second, it examines why it is difficult to formulate some laws as rules, in the process elaborating on the definition of rules and standards and the notion of frequency of application emphasized in Part I. Third, it assesses further the consequences of individuals' acquiring legal advice. The relevant question involves whether the costs of advice are warranted by the benefits from the changes in individuals' behavior that result from their being better informed about the law. Fourth, it discusses risk aversion. Finally, it analyzes objectives of the law other than deterrence. For example, when legal remedies are nonmonetary (injunctions, incarceration), individuals' behavior after adjuducation is directly affected by the law, in addition to or instead of being affected ex ante in anticipation of how the law will apply (the focus of the previous discussion).

Part IV comments on the interpretation of the analysis. It considers briefly the relevance of the branch of government involved in the promulgation and application of law, the role of judge and jury, abuse of power, political influences on rule formulation, and the process by which precedent is created. It also notes

17. Conversely, if the simple rule were preferable to the complex standard, it would make a difference whether the benefit arose from simplicity, from ex ante formulation, or from both. 
the ways in which rules and standards may change over time, and how laws regarding form (for example, formalities required in executing a will) and background laws (for example, laws providing contract remedies when parties do not specify one) may differ from laws regulating harm-producing behavior. Part $\mathrm{V}$ offers a brief conclusion.

\section{EX ante Versus $E X$ Post Creation of the LaW}

Section A offers a more precise statement, embodied in a simple illustration, of the three stages described in the Introduction. Section B analyzes how individuals might behave under rules and standards, assessing costs and benefits for each possibility. Section $\mathrm{C}$ describes how the analysis differs if standards are transformed into rules once they are applied, through the creation of precedents. Section D considers the fact that both individuals and architects of the legal system may choose how much effort will be devoted to predicting or giving content to legal commands. Section E comments on how the analysis of this Part suggests that the problem of creating the law can be interpreted as one involving the government's acquisition and dissemination of information.

\section{A. An Illustration}

The example involves three stages, as described in the Introduction. (1) The law is promulgated-that is, the government decides whether conduct will be governed by a rule or a standard. (2) Individuals make their choices. Since they are imperfectly informed, they first choose whether to acquire legal advice about the rule or standard. Next, they decide how to behave. (3) The law is enforced-that is, the rule or standard is applied. (A brief formal presentation of the example appears in the Appendix.)

1. Law Promulgation. The government enacts a law to regulate a harm-causing activity. It decides whether an aspect of the law is to be promulgated as a rule or as a standard. For example, it may use a rule to specify the level of damages to be awarded for a given harm, a standard of care, a list of prohibited acts, or the criteria an adjudicator should consider in making such determinations ex post. Alternatively, it may use a standard, thereby leaving any or all of such decisions for the enforcement authority. 
The problem is that the ideal content of the law with respect to these issues is not immediately apparent. ${ }^{18}$ Rather, some investigation and deliberation is required. It may be necessary to undertake an empirical analysis of the effect of a toxic chemical or to have some appropriate group deliberate about values (for example, how to value an invasion of privacy). To simplify the discussion, Sections A through $\mathbf{C}$ focus on the situation in which there is a given cost of determining the appropriate content of the law ex ante. Because of this cost, rules are more expensive to promulgate than standards. ${ }^{19}$

2. Choices of Individuals. Individuals are uncertain of the actual content of the law. ${ }^{20}$ That is, they only have estimates of the content of a rule or of the content an enforcement authority would give to a standard. They may, however, acquire legal advice-whether from lawyers, through self-study, or by other means. Because a standard requires a prediction of how an enforcement authority will decide questions that are already answered in the case of a rule, advice about a standard is more costly. ${ }^{21}$ Individuals can pursue one of two strategies. They can act based upon their best guess of the content of the law, or they can acquire advice and act based upon how the law actually would apply to their contemplated conduct. ${ }^{22}$

18. If it were, the issues addressed in this Article are of little significance, as the costs of promulgating and applying the law would be minimal. See infra Section III(A) (similarity of transparent standards to rules whose content is the same).

19. The analysis considers the case of a single jurisdiction. If another jurisdiction has already invested in promulgating a rule, which can simply be copied, there may be little additional cost in rules promulgation. Thus, jurisdictions might underinvest in (or delay) promulgation, attempting to free-ride on the investments of other jurisdictions. Projects designed to create model laws could mitigate this problem.

20. If individuals already know the content of the law, the situation is equivalent to one in which legal advice is costless. The analysis of subsection $\mathrm{B}(2)$ would be applicable (ignoring the advice cost differential). The possibility of transparent standards, see infra Section III(A), is essentially one involving costless advice.

21. See, e.g., POSNER, supra note 1 , at $44-45$. The possibility that standards may be more accessible than rules is discussed in Section III(A).

22. The discussion considers the case in which there is no particular bias in uninformed individuals' estimates and their guesses are unaffected by whether there is a rule or a standard. (If one assumed, for example, that individuals made systematic errors with standards but not with rules, rules would appear better, but this advantage would have no obvious connection to the inherent features of rules and standards.) This is related to the supposition in subsection 3 that an enforcement authority will give a standard the same content that would have been given to a rule $e x$ ante. 
3. Law Enforcement. The enforcement authority determines the sanction, if any, that applies to individuals' conduct. ${ }^{23}$ This process is costly, with the cost being greater if a standard governs because the adjudication will also require giving content to the standard. ${ }^{24}$

It should be emphasized that the "appropriate" content is taken to be the same ex ante and ex post, ${ }^{25}$ which implies that both the law promulgator (with a rule) and the law enforcer (with a standard) are able to determine the appropriate content ${ }^{26}$-although the cost need not be the same when incurred $e x$ ante or ex post. ${ }^{27}$ The motivation for taking this view-an often unrealistic one for reasons explored later $^{28}$-is to focus on certain inherent features of ex ante versus ex post creation of the law. Obviously, when one formulation more comports with underlying norms, it will be advantageous on that account. But, as will be seen, the nature of any such advantage cannot be assessed without first understanding the pure effects of ex ante versus ex post creation of the law. Also, as Section D emphasizes, the features of $e x$ ante versus ex post creation explored in Sections $\mathrm{B}$ and $\mathrm{C}$ will be an important determinant of when rules or standards are likely to be given content more in accord with underlying norms.

23. "Enforcement authority" can be thought of as including the entire process by which laws are enforced, whether by private lawsuits or government prosecution. Thus, the costs encompass the total costs of this process, and the framework applies equally to civil and criminal cases resolved in courts (whether by judge or jury), as well as to administrative tribunals, arbitration, and the like. See also infra Sections IV(A)-(B).

24. See also SCHAUER, supra note 1, at 229-30 (noting how the effort under rules tends to be less even when rules are presumptive rather than absolute).

25. Most of the analysis only requires that enforcement tribunals give content to the standard in an unbiased manner. See infra note 124 . The potential for inconsistent applications of standards is discussed in Section II(A). The possibility of changing circumstances is considered in Section IV(C).

26. For example, one might imagine that the same sort of inquiry would be conducted relying on the same experts or wise advisors. Note that a legislature promulgating a rule could, if it wished, impanel a jury of lay people and have lawyers present arguments to them, if it wished to enact popular understandings into law. Also, it could leave adjudication ex post to an expert panel consisting of the same individuals it would have consulted $e x$ ante in promulgating a rule. See infra Section IV(A).

27. See infra Section D.

28. See infra Section D; Parts II-IV. 


\section{B. Analysis}

The differences between rules and standards in this illustration depend on whether individuals will choose to acquire legal advice to guide their behavior. Individuals acting in their self-interest will acquire such advice only if its perceived value exceeds its perceived cost.

To determine the value of legal advice to individuals, it is necessary to compare how individuals would fare if they were uninformed with how they would fare if they were informed. Uninformed individuals act based on their best guess about how the law will apply to their contemplated conduct. Informed individuals act based on actual knowledge of the law. Thus, informed individuals might be deterred from conduct they would have undertaken if they had remained uninformed, ${ }^{29}$ which can occur when they learn that such conduct is illegal or subject to a higher sanction than they otherwise would have expected. Or, informed individuals might choose to undertake acts they would have been deterred from committing if they had remained uninformed. Both possibilities are of value to individuals. The value of advice, then, is simply the value of each possibility weighted by the likelihood of its occurrence..$^{30}$ Note that, in this example, the value of advice is the same under both rules and standards, as uninformed individuals do not believe that the mode of formulation affects the substantive content of the law. In addition, informed individuals are afforded the same guidance under either formulation, because a standard will be given the same content as a rule would have had, and advice about the content of each formulation is equally good.

How, then, does the presence of a rule or a standard affect individuals' decisions whether to become informed? The value of advice is the same under both formulations, but the cost of advice differs. In particular, advice is more costly under a standard. ${ }^{31}$

29. "Deterrence" should be construed broadly here. It includes changing the level or type of an activity or the manner in which an activity is conducted.

30. Risk aversion is ignored to simplify the exposition. As the discussion in Section III(D) suggests, the results are similar when individuals are risk averse.

If individuals are mistaken in their view about the value of advice, the analysis in this Part would be largely unaffected. Misestimates of the value of advice are relevant primarily with regard to the relationship between the private and social values of advice, noted briefly in subsection 3 and explored further in Section III(C).

31. The possibility that advice is more costly with rules is explored in Section III(A). 
Thus, there are three cases to consider: $:^{32}$ (1) Individuals do not become informed either under a rule or under a standard, because the value of information is less than the cost of advice under both a rule and a standard. (2) Individuals become informed both under a rule and under a standard, because the value of information exceeds the cost of advice under both a rule and a standard. (3) Individuals become informed under a rule but not under a standard, because the cost of becoming informed is less under a rule than under a standard.

Before proceeding with the analysis, it is useful to state the criterion for evaluation employed here. The social objective is taken to be the maximization of benefits net of costs. Benefits are the net gain to individuals from their acts; costs include the harm caused by individuals' acts and legal costs-the costs of promulgating the law, the costs of legal advice sought by individuals, and the costs of enforcement proceedings. ${ }^{33}$ The "appropriate" content embodied in a rule or that will be given to a standard by the enforcement authority provides the basis for assessing the weight to be given the benefits and harms of individuals' acts. ${ }^{34}$

\section{Individuals Do Not Become Informed Either Under a Rule} or Under a Standard. Because individuals do not become informed under either formulation of the law, information costs are not incurred. Moreover, uninformed individuals' behavior does not depend on whether a rule or standard prevails, so the benefits and harms of individuals' acts will be the same. Thus in this case, whether a rule or standard is preferable will depend solely on the differences in promulgation and enforcement costs.

The difference in promulgation costs favors standards, whereas that in enforcement costs favors rules. Which is greater depends on two factors. First, the cost differentials at the promulgation and enforcement stages need not be equal, for reasons to be explored

32. The discussion to follow will proceed as though a single case would apply to all individuals, for a particular law. More realistically, because individuals' available acts, opportunities to take precautions, knowledge of the law, and information costs will differ, each case might be relevant for some individuals.

33. Discounting for the passage of time is ignored. A higher discount rate tends to favor standards, which have a cost advantage at the first stage and disadvantages at the second and third stages.

34. That is, no independent standard of what constitutes good law is imposed. Rather, taking a stipulated set of objectives the law should embody, the analysis asks which formulation best implements them, taking into account legal costs. 
in Section D. (It is often useful to think of a benchmark case in which these differentials are the same, adjusting the argument for cases in which they are not straightforward.)

Second, one must take into account the frequency with which the two types of costs will be incurred. Promulgation costs are incurred once. In contrast, enforcement costs may be incurred repeatedly or never..$^{35}$ On one hand, a law may apply to an activity that is undertaken by many individuals: some federal income tax provisions apply to millions of individuals and billions of transactions. ${ }^{36}$ In such instances, rules tend to be preferable. Even if the promulgation cost differential significantly exceeds the enforcement cost differential in applying standards, rules may be much cheaper. ${ }^{37}$ On the other hand, a law-or, as is often relevant, a particular component of a law, possibly a highly detailed one-may have a small likelihood of applying to any activity; consider the example of myriad unique accident scenarios. Then, standards tend to be preferable. Even if they are extremely costly to apply, the significant likelihood that the particular application will never arise may make standards much cheaper. ${ }^{38}$

35. The frequency with which enforcement costs are incurred may itself depend on whether there is a rule or a standard. See also infra note 41 (differing behavior under rules and standards, as in case 3 , is another reason the frequency of enforcement actions may differ). If enforcement costs are indeed lower under rules, plaintiffs may be more likely to sue. (Plaintiffs also may have greater uncertainty about whether they have a viable case under standards, which could result in a change in the number and composition of cases: Some meritorious suits may not be brought and some suits that will fail might be brought.) The likelihood of litigation rather than settlement may also be affected. Lower litigation costs make litigation more likely under rules, but the greater predictability of outcomes makes litigation less likely. Some of these complications could be reflected in the measure of enforcement costs under each formulation. (For example, if litigation rather than settlement is more likely under standards, the enforcement costs under standards would simply be greater.) Factors affecting the frequency of litigation will affect both enforcement costs and compliance. (One could adjust damage awards or other aspects of the law to take this into account; for example, if fewer individuals would sue under standards due to higher litigation costs, one could have a more generous damages rule or less stringent proof requirements.)

36. The language of the discussion in the text suggests a finite number of repetitions, but the result is essentially the same if the number is infinite-as when the law will apply forever-and there is a sufficiently high discount rate on future costs and benefits.

37. This argument applies when the first adjudication does not create a precedent for future cases. See infra Section C.

38. This is in accord with the intuition that it is not worth providing with great care in advance for remote contingencies. See also infra Section III(B) (difficulty of formulating some laws as rules); note 78 (unforeseen contingencies covered in standards but not in rules); note 180 (example, involving fraud, of how a complex standard might result in 
2. Individuals Become Informed both Under a Rule and Under a Standard. Informed individuals behave in the same manner whether a rule or standard prevails, so again the benefits and harms from individuals' acts will be the same. Thus in this case, whether a rule or standard is preferable will depend on the differences in promulgation and enforcement costs (as in case 1)-and also on the difference in the cost of advice.

The difference in the cost of advice, which favors rules, parallels the difference in enforcement costs. The first factor concerns the magnitude of the differential and how it compares with the other differentials. The second involves frequency. Few (if any) or many individuals may incur costs in becoming informed about a law to guide their conduct; the greater the number of individuals likely to become informed, the greater the likelihood of rules being preferable.

Note that the number of individuals who incur the cost of legal advice may greatly exceed the number who are subject to complete enforcement proceedings. ${ }^{39}$ Some individuals who seek advice may choose not to commit acts subject to liability; others may commit acts that do not in fact cause harm (consider laws governing accidents); others may not be sued or prosecuted despite their liability; and most lawsuits are settled. Thus, even when advice is only moderately more costly under standards and enforcement proceedings are rare, there will be contexts in which the frequency with which advice is sought will make the advice cost differential decisive. ${ }^{40}$

little expenditure on enforcement).

39. Similarly, even if no enforcement proceeding would ever occur-and thus no adjudicator would ever have to apply the standard-the standard might suffer a substantial cost disadvantage.

40. A qualification is that the cost of legal advice may be decreasing over time. For example, a lawyer who has previously rendered advice on the same law would be able to offer advice to a subsequent client more cheaply. More generally, if a law governs a substantial amount of behavior, there may be conferences or publications through which information is disseminated among lawyers or to groups of clients. Nonetheless, it still seems plausible that the total costs will be greater as the number of acts increases, although this relationship need not have the simple linear form described here (in which a given cost of advice is multiplied by the number of individuals who acquire advice).

Related, there may be a public good aspect to legal advice. Those first to inquire about a problem, if billed for the full cost of researching the question, will pay a large amount, much of the benefit of which will flow to subsequent clients of the lawyer. If this occurred, there would be a disincentive to acquire advice initially. One way law firms 


\section{Individuals Become Informed Under a Rule but Not Under} a Standard. In this case, unlike the first two, the manner of formulation affects whether individuals acquire advice and how they behave. Thus, a comparison of rules and standards requires that one consider all components of social welfare. The analysis of promulgation and enforcement costs is similar to that in the first two cases, ${ }^{41}$ so the discussion here will focus on the remaining components.

Under a rule, but not under a standard, individuals acquire advice before they act. This is desirable in that behavior will be more in accord with legal norms, ${ }^{42}$ but undesirable in that an ad-

might address this problem would be to bill the first client much less (writing off much of the time, or perhaps doing much of the research before the first client arrives, while attending conferences or reading material on legal developments) and bill subsequent clients more (billing a flat amount for a type of advice, or charging higher hourly rates for more knowledgeable attorneys, to recover costs previously incurred). Competition among lawyers complicates the story. (It may limit feasible pricing schemes, and it also results in duplication of effort.) To the extent a public good problem remains, government subsidy of information about the law might be appropriate. See also infra Section E (problem of choosing rules or standards viewed as one involving government acquisition and dissemination of information); Section III(C) (discussing possible divergences between the private and social values of legal advice). Of course, the government does to some extent perform such functions, as when publications are made available for free or sold at rates that do not reflect the cost of compiling the information (but only printing and distribution costs).

41. There is, however, a complication concerning the enforcement cost differential. In cases 1 and 2, that differential was weighted by the expected number of cases. Because individuals' behavior was the same under a rule and a standard in each case, the expected number of enforcement proceedings was the same. But see supra note 35 (suggesting that the difference in enforcement costs and information available to plaintiffs may result in a different number of enforcement proceedings). In case 3, however, the expected number of cases may differ. Recall that informed individuals may be deterred more or less from committing acts subject to legal sanctions, depending on what they learn. Thus, in some instances there might be more or fewer enforcement actions under rules. (There would be more when uninformed individuals were deterred from committing acts subject to modest sanctions-more modest than they anticipated-and fewer when uninformed individuals would have committed acts they would not have committed if they knew the actual legal consequences.) Thus, the weight to be given the frequency component with regard to enforcement costs may be higher or lower than otherwise. See also infra note 117 (how sanctions should reflect enforcement costs).

42. The view that advised individuals will behave better than uninformed ones, as evaluated by the law about which they receive advice, is commonplace, but should not be accepted uncritically. See infra Section III(C) (discussing the private versus social value of legal advice).

Another respect in which advised individuals may behave more in accord with the law concerns the effects of uncertainty under a negligence rule. See infra note 123 (dis- 
ditional cost - the cost of advice-is incurred. In principle, the net could favor either rules or standards. ${ }^{43}$ But more can be said. We know that individuals only acquire information when its benefits exceed its costs. Thus, the value of advice to individuals exceeds its cost. As a result, rules would be preferable on account of these components whenever the private value of advice-which takes into account both the benefit from the act itself and the legal sanction (if any) the individual expects to pay-equals the social value of advice. The discussion in Section III(C) identifies contexts in which this equation of private and social values of advice holds, and others in which it does not. ${ }^{44}$

To enter these components into the framework, recall that in case 2 the advice component involves multiplying the number of individuals who would seek advice by the differential in the cost of advice under rules and standards. In this case, the advice component instead involves multiplying the number of individuals who would seek advice by the differential between the social value of advice and the cost of advice under rules.

cussing the range of laws that should be seen as involving a negligence rule for present purposes). If, for example, there is uncertainty concerning what an adjudicator would deem to be due care, there may be a tendency for individuals to take care that is excessive relative to the expected due care requirement, although it is also possible that individuals would take less care than the expected due care requirement. See, e.g., STEVEN SHAVEll, ECONOMIC ANALYSIS OF ACCIDENT LAW 79-83, 93-97 $(198 ; \rightarrow$ Richard Craswell \& John E. Calfee, Deterrence and Uncertain Legal Standards, 2 J.L. EcON. \& ORGANIZATION 279 (1986). The existence of a tendency toward excessive care depends, however, on how the causation requirement is applied. See Marcel Kahan, Causation and Incentives to Take Care Under the Negligence Rule, 18 J. LEGAL STUD. 427 (1989); see also infra note 125 (if uncertainty is resolved ex ante with some error, substituting a rule for a standard may make error more predictable and thus behavior may be worse).

43. In some contexts, it might be imagined that individuals are simply aware of the content of rules, so no cost is incurred, in which case the failure to become perfectly informed under standards implies an unambiguous loss. For example, the preference for rules in the context of substantive criminal law seems to reflect the view that rules will be known but standards may be applied in ways individuals would not anticipate. See, $e \rightarrow$ Jonathan C. Carlson, The Act Requirement and the Foundations of the Entrapment Defense, 73 VA. L. REV. 1011, 1024 (1987).

44. If the private value of advice is less than its social value, the conclusion that rules are preferable with regard to the acquisition of advice also follows: The magnitude of the social gain with regard to these components would be even greater than suggested by private valuations. If the private value of advice exceeds its social value, the conclusion would be different only if the social value were sufficiently low that it were less than the cost of advice-which is possible. 
In summary, the greater the frequency with which a legal command will apply, the more desirable rules tend to be relative to standards. This result arises because promulgation costs are borne only once, whereas efforts to comply with and action to enforce the law may occur rarely or often. Rules cost more to promulgate; standards cost more to enforce. With regard to compliance, rules' benefits arise from two sources: Individuals may spend less in learning the content of the law, and individuals may become better informed about rules than standards and thus better conform their behavior to the law.

\section{Precedent}

There is an additional aspect of enforcement activity that is important to the problem addressed in this Article: whether, under a standard, the enforcement authority's first adjudication constitutes a precedent for future enforcement proceedings. Section B examined the case of no precedent, in which the standard is totally unaltered by enforcement proceedings. ${ }^{45}$ One can contrast the case in which the first enforcement proceeding essentially transforms the standard into a rule. ${ }^{46}$ That is, in subsequent enforcement proceedings, courts simply apply the precedent rather than engaging in an inquiry concerning appropriate legal treatment-and access to this precedent costs no more than if the law had been promulgated as a rule in the first place. Similarly, legal advisors find it equally costly to consult a precedent as to consult a law initially promulgated as a rule, so that the costs of legal advice under a rule and a standard are equal once the precedent is established. (The discussion here focuses on polar cases for convenience.")

45. One can imagine a jury verdict that has no formal precedential value, is not evidence for future cases, and is not even accessible to legal advisors when researching a legal question.

46. See, e.g., HART, supra note 1, at 129 ("Where the decisions of the court on such matters [regulated by standards] are regarded as precedents, their specification of the variable standard is very like the exercise of delegated rule-making power by an administrative body, though there are also obvious differences."); POSNER, supra note $9, \S 20.1$, at 539 ("[A]n accumulation of precedents dealing with the same question may create a rule of law having the same force as an explicit statutory rule."). For jurisprudential discussions of precedents as rules, see Larry Alexander, Constrained by Precedent, 63 S. CAL. L. REV. 1 (1989); Schauer, Precedent, supra note 5.

47. It is straightforward to adjust the analysis to account for intermediate cases-for example, when precedents and laws initially promulgated as rules are not equally accessible, or when only some of the activity governed by a standard is covered by the prece- 
When the first adjudication does create a precedent, only the first enforcement proceeding and individuals' actions that precede the completion of that first proceeding need be considered, as subsequent events are identical under both rules and standards. Each of the three cases from Section B is now briefly reexamined. ${ }^{48}$

In case 1 , in which individuals do not acquire legal advice under either rules or standards, the factor of repetition is removed. Because there will be only one enforcement proceeding in which costs differ, one compares the cost differential for one proceeding, ${ }^{49}$ which favors rules, with the cost differential in promulgating the law, which favors standards. (Observe, however, that the cost of an enforcement proceeding under a standard may be higher when the result will be a precedent than when it will not. ${ }^{50}$ )

In case 2, in which individuals acquire legal advice under both rules and standards, the factor of repetition is removed for enforcement proceedings. But repetition may still be relevant with regard to individual behavior because many individuals may need to acquire advice before the precedent is established. (Reasons for this were noted in subsection $\mathrm{B}(2)$ and will be explored further in subsection IV(B)(1).)

Case 3 parallels the second. The factor of repetition remains present only for individual behavior before the precedent is established. As in the case of no precedent, the differential here favoring rules, for each individual, consists of the value of advice (which reflects changes in behavior to comply with the law) minus the cost of advice under rules.

In summary, if the first adjudication under a standard constitutes a precedent for future enforcement proceedings and thereby transforms the standard into a rule, the differences between pro-

dent. See infra subsection IV(B)(1). Such intermediate cases are believed to be important. Thus, arguments that civil law systems are superior to common law ones or that favor codifications, restatements, and other summaries of precedent are motivated by differences between the accessibility of precedents and statutes (or other compilations of the law). See, e.g., Gregory E. Maggs, Reducing the Costs of Statutory Ambiguity: Alternative Approaches and the Federal Courts Study Committee, 29 HARV. J. ON LEGIS. 123, 126 \& n.8 (1992).

48. The presentation in the Appendix examines each case with and without precedent.

49. This, however, must be discounted for the possibility that no enforcement proceeding would ever occur.

50. See infra subsection $\mathrm{D}(3)$. 
mulgating the law as a rule and as a standard are diminished. But they are not eliminated. Frequency will still be an important dimension. If acts subject to the law are unlikely to arise, the possibility of saving the costs of giving content to the law tends to favor standards. If acts will be frequent, there may be substantial costs in the interim under standards - costs of advice or costs reflected in behavior that does not comply with the law-that are avoided under rules.

\section{The Degree of Effort Devoted to Rule Creation, Legal Advice, and Enforcement}

The discussion thus far has examined the situation in which the promulgation of a rule entailed a given additional cost and resulted in a determination of the "appropriate" content of the law. Similarly, both legal advice and enforcement under a standard involved a given additional cost and properly predicted or determined the law's content. Achieving complete and proper assessments is usually infeasible and, even if possible, unwise due to the cost involved. Rather, it generally would be sensible at each stage to determine how much additional cost to incur as a function of the benefits that result. This Section reconsiders each stage of the analysis in light of this consideration. ${ }^{51}$ It also emphasizes factors that may influence the relative costs of inquiry at different stages.

1. Law Promulgation. Presumably, efforts to determine the appropriate content of the law are subject to diminishing returns. Further investigation and greater deliberation are almost always possible, but after a point would yield little improvement in the quality of the resulting law. ${ }^{52}$ The value of effort in designing a rule depends on the frequency of behavior subject to the rule, for reasons explained in Section B. If the rule will govern the conduct of many individuals, most of whom will acquire advice about the

51. The problem of the optimal degree of investment in promulgating or applying rules or in seeking legal advice has, to my knowledge, received little attention. Most relevant is Louis KAPLOW \& STEVEN SHAVELl, ACCURACY IN THE ASSESSMENT OF Damages (Harvard Law School Program in Law and Economics Discussion Paper No. 116, 1992). This problem is related to the question of the optimal complexity of laws addressed in Section II(C).

52. The quality of the law can be understood as reflecting how closely it conforms to underlying norms or to the likelihood with which it conforms. 
rule's content, it will be more important that the rule closely reflect the law's underlying norms. If the rule is unlikely to apply to many or any acts, or if individuals would not bother to consult it before acting, relatively little should be spent designing it. ${ }^{53}$ Note that this result softens the disadvantage of rules in such instances by reducing the promulgation cost differential; at the same time it reduces the benefit of rules with regard to inducing individuals to behave in a socially optimal manner if the rules to which they will conform are less in accord with underlying norms.

2. Choices of Individuals. The analysis for legal advice is similar. Because resources devoted to legal advice that determines the content of a rule or predicts the content of a standard will be subject to diminishing returns, individuals' decisions concerning legal advice involve questions of degree, rather than the all-ornothing decision described in the example in Section B.

Observe that when substantial expenditures will be made in designing a rule because it will apply to many individuals' conduct, the effort at the rule's promulgation stage will probably be greater than the effort an individual would choose to expend to have a lawyer predict the content of a standard, because the individual would be concerned only with the single instance of his own conduct. In this case, one might expect behavior to conform more closely to underlying norms under rules than under standards (even if more might actually be spent on legal advice under standards, due to the higher cost of prediction of standards compared to consultation of rules) ${ }^{54}$ Conversely, if little effort is to be devoted to designing a rule because it might never apply, an individual subject to a standard might expend more effort (in predicting how the standard will be given content) once the event has actually arisen, suggesting better behavior under standards. ${ }^{55}$ Thus, con-

53. Of course, the more important the conduct subject to the law, the more should be spent at all stages for any given degree of frequency.

54. The possibility that standards would be more accessible than rules, with the result that behavior conforms better under standards, is explored in Section III(A).

55. These arguments abstract from possible differences in the cost of designing rules and predicting standards. One might imagine, for example, that the former is cheaper because the latter requires prediction, or that the latter is cheaper because one need only consider a single set of facts or because the facts are known to the individual but must be investigated by the government. Regardless, the dimension of frequency emphasized in the text will be important and will have the tendency suggested. See also supra note 40 (discussing public goods aspect of legal advice). 
sidering variations in effort at this stage affects both the advice cost differential and the assessment of behavior under rules and standards.

3. Law Enforcement. Begin with the situation examined in Section B, in which the first application of a standard would not be a precedent for future cases. Then, the degree of effort that should be made in an enforcement proceeding to give content to a standard should reflect the fact that the determination will be relevant to one case. ${ }^{56}$ Therefore, when a law applies to frequent conduct, less effort should be devoted to giving content to standards than when designing rules, suggesting that rules will give rise to behavior more in accord with underlying norms. ${ }^{57}$ Conversely, when acts governed by a law (or a particular detail of a law) are unlikely to arise, more effort should be devoted to giving content to standards.

A number of important qualifications should be emphasized. First, how much effort should be spent giving content to a standard ex post in an enforcement proceeding depends importantly on the extent to which individuals would expend effort ex ante to predict how the standard would apply to their contemplated conduct. For example, if individuals would spend little to become informed, and thus would not be in a position to anticipate the actual content an adjudicator would supply, efforts devoted to more careful application of a standard would be wasted..$^{58}$ As a

56. The discussion emphasizes the effort that should be made. In the legal systems of the United States and some other countries, the effort in court adjudication is typically determined by a combination of the parties' expenditures on the case (which reflects private interests), see KAPLOW \& SHAVELL, supra note 51, the overall workload of the court, whether the question is one of law or fact, and, with questions of law, the degree to which the judge(s) find the matter interesting or important. Only some of these factors are related to the socially appropriate level of effort, and even those factors may have only a modest connection.

57. Consider Schauer's suggestion that decisionmaking without rules is subject to errors arising from the adjudicator's lack of understanding. See SCHAUER, supra note 1, at 150. This view will be correct either when the sorts of individuals who are decisionmakers are less competent (perhaps because less expert) than those who design rules, see infra Section IV(A), or, as emphasized in this subsection, when the decisionmaking environment under standards involves less effort being applied.

58. If, regardless of the content given standards, individuals act based on gross estimates, an adjudicator might as well base its decision on such gross estimates. See KAPLOW \& SHAVELL, supra note 51. Some elaboration of this issue appears in Section III(C). See also infra Section III(D) (discussing risk aversion). 
related matter, if one wishes to induce individuals to become informed to some extent at the time they act, ex post expenditures will be necessary to ensure that an ex ante incentive to become informed exists. The more precise the adjudicator will be ex post, the more precise individuals will be induced to become ex ante. In this context, the value of a more accurate ex post adjudication lies in its ex ante effect on behavior. ${ }^{59}$ Thus, the appropriate degree of effort in giving content to standards will reflect both that one actual case is involved (not many cases and not the mere possibility of a case) and that effort counts for the one case not in the abstract but rather to the extent it creates ex ante incentives for individuals to adjust their conduct. ${ }^{60}$

Second, the cost of inquiry into the appropriate content of the law need not be the same at the promulgation and enforcement stages. Most obviously, inquiry may be cheaper in an enforcement proceeding because only one set of facts need be considered, ${ }^{61}$ or because the act itself provides information. ${ }^{62}$ These factors would often be most important precisely when standards are more likely to be preferable generally-when acts governed by a law vary greatly in relevant characteristics, and each is unlikely to occur. ${ }^{63}$

59. See also Section III(E) (discussing objectives of the law other than the control of behavior ex ante).

60. In a single case, there is, of course, no ex ante effect on the actor's conduct from the actual ex post decision concerning effort in applying the standard. More broadly, however, the legal system will become known-to some extent generally and to some extent with regard to particular laws-for the degree to which it supplies content to standards in enforcement proceedings. The discussion in the text proceeds as though actual practice over time will determine perceptions. (To the extent that there are divergences, the effect on the analysis would be straightforward.)

61. For example, if a driver's speed was 100 miles per hour, one need not decide whether the ideal speed limit is 55 or 60 miles per hour.

62. See, e.g., infra note 78 (concerning events difficult to foresee); Section III(B). With technological uncertainty, the very fact of an accident or a pattern of harm may provide information that did not exist before the act was taken. (It need not provide such information: A substance may have been previously suspected to be carcinogenic, and the available tests may be no more reliable than previously.) Note that both of these factors seem more plausible with regard to fact scenarios than with regard to which norms are appropriate-that is, for example, whether only safety and time or also energy conservation should be considered in designing laws governing driving.

63. Of course, there may be acts that will arise frequently in the future about which little is known, as when there is a technological advance. When future frequency corresponds with past frequency, however, there will usually be substantial information available that can be consulted when designing a rule. Even when acts are new, if latency periods are not long, a rule designer might conduct tests to determine previously unknown effects. This would tend to be desirable if many such acts are expected to be 
Note, however, that the lower cost of inquiry in applying a standard does not imply that the standard should always be applied more carefully on that account. If the application will govern only the single case or if it could not have been anticipated at the time the individual decided to act (perhaps because the consequences were not apparent until afterward), ${ }^{64}$ there would be little value in using the newly available information, even if incorporating it into a decision is cheap. Also, in some cases inquiry may be cheaper when designing rules than when applying standards, due to economies of scale with regard to the former. ${ }^{65}$

Finally, consider the situation in which the application of a standard will produce a precedent. Then, the appropriate degree of effort in giving content to the standard at the enforcement stage is determined in much the same manner as for a rule at the promulgation stage. ${ }^{66}$ Thus, whether a decision will constitute a precedent affects the degree of effort an adjudicator should expend in giving content to a standard. Also, note that this analysis bears upon when the creation of precedent is appropriate. If an initial decision to promulgate a law as a standard rather than as a rule is an appropriate judgment based on the relevant costs and benefits, rather than, say, a legislature's decision to delegate the question to the courts, ${ }^{67}$ converting a standard to a rule via precedent would be sensible only if assessments of the relevant factors differed. These assessments might differ if, for example, the adjudicator

committed in the future. This may be one of many reasons that drug regulation requires tests prior to approval.

64. In contrast, if the facts that could not be readily or cheaply anticipated by the promulgator of a law are readily apparent to the actor, it is desirable that individuals anticipate that an adjudicator will take these facts into account. $\rightarrow$ Steven Shavell, Liability and the Incentive to Obtain Information About Risk, 21 J. LEGAL STUD. 259, 263-66 (1992).

65. See infra note 101 .

66. A difference is that it is known with a standard that the case has arisen at least once. In addition, there are the differences noted previously concerning the cost of promulgation. Yet if the precedent will be confined to particular facts (for example, driving at 100 miles per hour is declared illegal without comment on driving 90 miles per hour), the precedent will be narrower than a rule (for example, one that sets the speed limit at 55 miles per hour) -in which case not as much effort would be appropriate (because the frequency with which the precedent will apply is lower). Presumably, this is relevant to courts' inclination, discussed in subsection IV(B)(1), to decide cases narrowly; they may have good information generated by the case with regard to the situation before them, but may have little information regarding other cases.

67. See infra Section IV(A); subsection IV(B)(1). 
learns that a particular incident has indeed arisen and so might be able to assess the incident at lower cost than would have been possible ex ante. ${ }^{68}$

The foregoing considerations suggest that appropriately designed rules and standards will be imperfect and that individuals' behavior will imperfectly reflect the content of the law. ${ }^{69}$ The preceding discussion casts further light on how imperfect rules and standards would be, the circumstances in which individual behavior will be better under one formulation or the other, and the magnitude of the cost differentials with regard to promulgating the law, obtaining legal advice, and enforcing the law.

This discussion speaks largely in an all-or-nothing manner: Should the law be promulgated as a rule or a standard, and how carefully designed and applied should either one be? Similar analysis applies to the question of how many factors should be included in a rule or a standard, as will be noted in the discussion of simplicity versus complexity in Part II. As a related matter, some aspects of a law-those likely to apply to many acts-are best included in a rule, whereas others-those unlikely to apply-are best left to a standard. ${ }^{70}$

68. Related, accumulated experience may change estimates of frequency or other factors. See infra note 160 . Otherwise, as when the conduct subject to the law is frequent and the costs of determining the appropriate content of the law are unchanged, precedent is necessarily inferior for the reasons noted in Section C: In the interim, costs spent on legal advice may be higher, and conformity may be lower. See infra subsection IV(B)(1). Therefore, when events or technological changes decrease the costs of designing the law, it may be better to promulgate a rule at that time than to wait for a precedent reflecting the new information to be established.

69. As examined in Part II, commentators frequently note that the costs of ex ante rule creation may be great, with the result that imperfect, over- and underinclusive rules will be promulgated. Yet they assume that ex post it will be optimal to be more precise (even perfectly precise). (Compare the discussion in Section II(D) of whether rules or standards tend to be more detailed in operation.) In the absence of the sorts of factors discussed above, however, this result can arise only if the legal system inefficiently expends more ex post in making single applications of standards than it would expend ex ante in designing a rule that may be applicable to the behavior of many. If the system actually operates this way when it should not, standards are worse in operation than in principle. The additional accuracy ex post-which may not even be particularly valuable in governing behavior ex ante-is by assumption more costly than it is appropriate.

70. See infra Section III(B). 


\section{E. Creation of the Law as Information Acquisition and Dissemi- nation}

The analysis of this Part suggests that the problem of promulgating and applying rules and standards can be understood as one involving the government's acquisition and dissemination of information about the appropriate content of the law. ${ }^{71}$ Whether a law should be given content ex ante or ex post involves determining whether information should be gathered and processed before or after individuals act. ${ }^{72}$

When the government promulgates a rule, it gathers information before individuals act and announces its findings. ${ }^{73}$ As a result, the information is available to individuals when they act; individuals then may be guided by it and spared the expense of producing such information themselves. ${ }^{74}$ In addition, the information is available to adjudicators, who realize similar advantages.

Whether the ideal time to acquire and disseminate information is ex ante or ex post depends, most importantly, on the frequency with which the information will be used. The savings from a single ex ante investigation will be great when the use of the results will be frequent, but will be negligible when the use of the results will be unlikely. Also, to the extent there are economies of scale in information acquisition, ex ante wholesale investments may be superior. ${ }^{75}$ But if there are advantages in delay because information will be easier to acquire at the time individuals act or cases

71. See also infra note 196 (suggesting that government's choice between rules and standards may be illuminated by considering how complex private organizations formulate internal operating procedures). The term "information" is used here to include anything relevant to reaching a better decision, whether facts or understandings that can be improved through greater discussion and reflection.

72. Similarly, the question of how much effort to devote to rule-creation and to giving content to standards in enforcement proceedings involves determining the appropriate investment in information.

73. Whether the form of the announcement is legally binding in all of its particulars or is merely suggestive may be less important than whether the information is gathered and published. See supra note 5 (discussing whether binding rules are possible); infra Section III(B) (de-emphasizing the language of the law); subsection IV(B)(3) (noting that the government's conducting and publishing of a study on hazardous substances may have an effect similar to the adoption of a rule embodying the study's results).

74. See also supra note 40 (discussing public goods problem in private production of such information).

75. See infra note 101 . 
are adjudicated, ex post investments would tend to be preferable. $^{76}$

\section{RULES VERSUS STANDARDS AND COMPLEXITY: ON OVER- AND UNDERINCLUSIVENESS}

This Part attempts to clarify understanding of the view that rules tend to be over- and underinclusive relative to standards, and more generally, the notion that differences between rules and standards typically involve differences of substance as well as of form. Section A offers a vocabulary for addressing this issue, one that allows the complexity of a legal command and the time at which it is given content (ex ante versus ex post) to be distinguished conceptually. Section B explains why this distinction is important. Section $C$ briefly discusses how complexity ought to be analyzed. Section D concludes by commenting on whether there are reasons to expect standards to be applied in a systematically more or less detailed manner than rules.

\section{A. Distinguishing Complexity from the Choice Between Rules and Standards: Definitions}

It is useful to have a way to determine when rules and standards have the same content and thus the same degree of complexity. The following construction permits this. For any standard, consider the actual outcomes that would arise for all possible cases. Now, define the "rule equivalent to the standard" (or the "de facto standard") as that rule which attaches these same outcomes to these cases. ${ }^{77}$ Thus, if a standard is compared to the rule equivalent to the standard, the content and level of detail are held constant. (For example, using the illustration in the Introduction, a standard that on its face admitted dozens of factors but in practice involved only two would be compared to a rule containing only those two factors.)

Note that nothing has been said about the practicality of the rule that would be equivalent to the standard, because it is merely

76. See supra subsection $\mathrm{D}(3)$.

77. One could also operate in the reverse direction and inquire into the "standard equivalent to the rule." Thus, as with the example in Part I, for a given rule one could imagine a standard that must be applied with the same level of detail, with the content of the standard to be determined by the same sort of investigation that determined the content of the rule. 
an analytical construct that will demonstrate its usefulness in the discussion to follow. ${ }^{78}$ One problem deserves brief attention: There may be inconsistency under a standard ${ }^{79}$-as one might expect, for example, when decision is by general jury verdict. ${ }^{80}$ This could involve occasional aberrations or situations in which, say, a standard yielded one result half of the time and a different result the rest of the time..$^{81}$ Even for this extreme case, there ex-

78. One might object that the rule equivalent to the standard would be impossible, because not every contingency can be anticipated. See SCHAUER, supra note 1, at 83-84 (discussing the possibility that a rule might incorporate all relevant distinctions but still be vulnerable to the problem of unanticipated events). Because this construct is hypothetical to begin with, this is not decisive for the main argument that follows. (To establish it, one need not actually write what the rule equivalent to the standard would be.) Moreover, one can think of cases in which contingencies cannot be foreseen as those in which design of the relevant components of the rule would be prohibitively costly, rather than "impossible." Section I(D) examines the question of how much should be invested in designing rules. It is apparent that sufficiently remote contingencies that cannot be addressed except at high cost should not be included in rules in any event. If, as a result, the best rule would be less detailed than the rule equivalent to some particular standard, a comparison of the rule to the posited standard would require consideration of both differences in the level of detail (complexity) and differences between ex ante and ex post creation. This is precisely the sort of analysis advocated in the remainder of this Part. And, to be more concrete, such analysis suggests that the likelihood of important contingencies whose relevant contours cannot readily be anticipated when promulgating the law (but which would be understood by the time individuals subject to the law decide how to act) is a factor favoring the (implicitly) complex standard. Thus, there is nothing in the analytical construct offered in the text that is inconsistent with this sometimes important possibility. See also infra Section III(B) (concerning the difficulty of formulating some laws as rules).

There is also no necessary contradiction between this construct and the view that rules "are necessarily general rather than particular." Schauer, supra note 4, at 647, 649-51. Particularity is a matter of degree. Given the limits of language and a finite text, no feasible rule could ever be infinitely particular. Still, for all cases that might arise, one could in principle note the outcome and imagine the rule that stipulated such an outcome given all the particulars of the case. Moreover, as emphasized in this Part and in Section I(D), in practice standards will not and should not be applied in a manner that accounts for all conceivably relevant particulars.

79. There will be some inconsistency in practice under a rule as well, although generally less.

80. Other decisionmakers also can be quite inconsistent. For example, in a study of sentencing by district court judges in the Second Circuit, judges awarded widely disparate sentences in identical hypothetical cases. See ANTHONY PARTRIDGE \& William B. EldRIDGE, THE SECOND CiRCUIT SENTENCING STUdY 5-11 (1974).

81. Such inconsistencies might reflect differences in the individual jurors selected, the parties' lawyers, or any number of other factors. One could specify these features of each case and simply make them part of the "rule equivalent to the standard." If the feature was normatively relevant, this would be appropriate. If not, presumably the simpler rule that ignored the factor would be superior on grounds of both its content and its simplicity. 
ists an equivalent rule-a rule that specifies the two results as possibilities, with the actual result to be determined by the flip of a coin. Thus, the problem of inconsistency does not undermine the conceptual construction, which allows one to consider the desirability of ex ante versus ex post creation of the law, holding the content of the law constant. (Needless to say, in most contexts the randomized rule equivalent to the standard would be inferior to a rule that selected one of the two outcomes for all cases, or to a single, consistent compromise between the two outcomes. ${ }^{82}$ Such a deterministic rule, in turn, would be superior to the hypothesized standard in this regard.)

\section{B. Distinguishing Complexity from the Choice Between Rules and Standards: Implications}

Using the construct of the rule equivalent to the standard, one can compare rules and standards of differing content (as they are applied) in two steps. First, one can compare the standard to an equivalent rule, using the analysis of Part $I^{83}$ Second, one can compare this equivalent rule to the rule under consideration by analyzing their differences in details. (Alternatively, one could compare the rule to an equivalent standard and then compare this equivalent standard to the standard under consideration.)

Many discussions of rules versus standards combine-or confuse-these two concerns. In particular, simple rules are often

82. Consistency might be favored by considerations of risk aversion, fairness, or uncertainty that makes settlement before trial more difficult. The last reason is noted in

$\rightarrow$ Ehrlich \& Posner, supra note 1, at 265 .

83. The discussion of rules and standards in Part I focuses exclusively on the question of whether content is determined ex ante or ex post. Nothing depended on whether the comparison involved a simple rule and a simple standard or a complex rule and a complex standard. The analysis assumed only that the content, and thus level of detail, were held constant. For example, it may be that with a complex rule, the government must promulgate (stage one), a lawyer must consult (stage two), and a tribunal must apply (stage three) a detailed web of provisions, rather than, say, a simple statement of whether an act is prohibited. Likewise, with a complex standard, a web must be developed and applied ex post (stage three) and anticipated by lawyers (stage two). Presumably, each of these processes will involve a greater cost than with a simple rule or standard. Nonetheless, the relevant analysis would be the same. Of course, for a standard and corresponding rule, it may be that some details would better be promulgated in a rule and others left to an adjudicator using the formulation of a standard, rather than all being crafted in one mode, particularly because some details will concern frequently conducted activities and others infrequently occurring ones. See supra note 6 and accompanying text; infra Section III(B). 
compared to complex standards; most commonly, it is asserted that rules tend to be over- and/or underinclusive relative to standards. ${ }^{84}$ The reason for this suggested difference is that rules limit the range of permissible considerations whereas standards do not. Observe, however, that a rule cannot be over- or underinclusive relative to a standard if one is comparing the standard to the rule equivalent to the standard. Implicitly, therefore, commentators must be comparing a complex standard to a simple rule-that is, a rule simpler than the rule equivalent to the standard. Section D explores whether rule systems are indeed universally simpler than standards, as each formulation actually would be created and applied in practice. The focus here is on how one should compare rules and standards that indeed differ in complexity.

Whether a complex standard is preferable to a simple rule depends on the combined effects of complexity and promulgation of the law as a rule versus as a standard (ex ante versus ex post creation). When a complex standard is said to be preferable to a simple rule, it may be that complexity and use of a standard are both independently and unambiguously desirable. ${ }^{85}$ But there are two additional possibilities.

First, it may be that a simple standard (one equivalent in content to the simple rule under consideration) is undesirable compared to the simple rule, whereas a complex standard is desirable. This suggests that the desirability of the complex standard arises from its complexity, not from its promulgation as a standard. In this case, a complex rule may ${ }^{86}$ be even better than the com-

84. See sources cited supra note 13. The tendency to make this comparison has been noted in Schlag, supra note 5 , at 423 . Colin Diver indicates the possibility that a standard "may be under- or overinclusive in application, because its vagueness invites misinterpretatio $\rightarrow$ Diver, supra note 1 , at 73 . This possibility may refer to the problem of inconsistency, discussed in Section A. To assume that this is the only manner in which a vague standard may be over- or underinclusive, however, is misleading. As Diver notes, see id. at 69 , an open-ended standard may be interpreted in a simple manner. This, however, would be a "misinterpretation" only if it indeed were optimal to give it more precise content in practice. As the discussion in Section $C$ indicates, this need not be the case.

85. Similarly, if the simple rule is preferable, it may be that simplicity and use of a rule are both desirable, or that only one dimension favors formulation as a simple rule.

86. This need not be the case, however, because of synergy. For example, designing the complex rule may be expensive and the likelihood of application for each of the detailed components may be sufficiently small that a complex standard is better, whereas the analogous balance is otherwise for the simple rule and simple standard-because the provisions would be rather general, applying to many actors. 
plex standard. ${ }^{87}$ Thus, requirements for handling different hazardous substances might better be promulgated as complex standards than as simple rules, which ignored important differences among substances, but complex rules may be best of all (as noted in the example in the Introduction).

Second, it may be that a complex rule is undesirable, but a complex standard desirable. This suggests that the desirability of the complex standard arises from its promulgation as a standard, not its complexity. In this case, a simple standard-meaning one that in practice is applied using little detail-should be considered. ${ }^{88}$ For example, whether an exception to a town's requirement that people keep off the grass in the public square should be made in the event that the President unexpectedly visits, might best be left to a standard, because the event is so unlikely to arise. Thus, a simple standard that considers only a few salient factors might be preferable, since the expectation that an adjudicator would take into account myriad subtle factors ex post would be unlikely to affect the crowd's behavior in any event.

\section{Analyzing the Problem of Over- and Underinclusiveness}

Comparing the desirability of a complex standard that is accordingly costly to apply with a rule that is sometimes over- and underinclusive because of its simplicity raises two separate issues: rules versus standards (ex ante versus ex post creation of the law), already examined in Part I; and the appropriate level of detail, which requires a separate analysis. In order to compare two rules (or two standards) having different levels of detail, one needs a framework for analyzing the effects of detail in laws. Because this problem is not the primary focus of this Article and because it has

87. Unlike most other commentators, Colin Diver notes that when over- and underinclusion is an important problem, it is optimal to employ either highly flexible formulas (complex standards) or intricate regulatory formulas (complex rules). ، $\rightarrow$ Diver, supra note 1 , at $74-75$.

88. Again, because of synergy, this implication need not follow. Thus, when there are many possibilities, each unlikely to arise, a complex rule may be too expensive because of promulgation costs and a simple standard may be of only modest benefit because it does not respond to the range of possibilities, whereas a complex standard would be best of all. 
received attention in other work, ${ }^{89}$ only a brief summary of basic principles is offered here.

To illustrate, consider what law should be promulgated to regulate a given set of activities-for example, the discharge of a certain class of chemicals. Most of the chemicals cause a known level of harm; the remainder of the chemicals are harmless. But it is not immediately apparent which of the chemicals are the harmful ones.

Compare two laws. A simple rule holds individuals discharging any of the chemicals in this class strictly liable for damages equal to the average harm (that is, the harm multiplied by the fraction of discharged chemicals that are harmful). A complex standard holds individuals "appropriately" responsible: An adjudicator will conduct an inquiry, the result being that those discharging chemicals that are actually harmful will be held strictly liable for damages equal to the level of harm caused, and those discharging harmless chemicals will not be held liable. Thus, the standard makes an ex post, case-by-case determination of which chemicals are harmful. The standard is complex compared to the rule, because the rule does not distinguish among chemicals in this class.

Observe that the simple rule is both over- and underinclusive compared to the more complex standard. The simple rule overdeters discharges of harmless chemicals covered by the law by subjecting them to positive liability. Some harmless discharges will therefore be deterred despite their desirability. The simple rule underdeters discharges of harmful chemicals covered by the law by subjecting them to liability for less than the actual harm they cause. Some harmful discharges will be made even though their benefit is less than the harm they cause.

To determine whether the simple rule or complex standard is superior, consider the differences in costs and behavior under the two laws. At the promulgation stage, there would be little difference. Although a rule is more costly to promulgate than a standard of the same degree of complexity, this rule is simple. There is no ex ante investigation to define which of the chemicals are harmful.

89. See Louis KaPlow, A Model of the Optimal COMPleXity of Rules (Harvard Program in Law and Economics Discussion Paper No. 97, 1991). The analysis in that piece does not consider promulgation costs, although incorporating them would be straightforward. 
At the stage concerned with individuals' behavior, one can identify two possibilities (or, two sets of individuals). First, individuals may not become informed with respect to the complex standard, because of the cost of determining whether the chemical they would discharge is harmful. ${ }^{90}$ Suppose that they know only that the chemical they contemplate discharging is subject to the standard, which implies an expected liability equal to the average harm (which is precisely how they expect to be treated under the simple rule). In this instance, their behavior will be the same under both formulations of the law. At the enforcement stage, applying the complex standard will be more costly. But this will be a waste, because behavior will not be improved by avoiding overand underinclusiveness. As a result, the simple rule would be superior. Achieving a better fit between the law and behavior is accomplished only if individuals are induced to conform their behavior to the legal norm. ${ }^{91}$

Second, consider individuals who do become informed with respect to the complex standard. They expend resources on advice and, upon learning whether their chemical is indeed harmful, may be induced (depending on what they learn) to behave differently. Suppose that this change in behavior is desirable, even when taking into account the cost of advice. ${ }^{92}$ Then, with regard to the second stage, at which individuals' decisions are made, the complex standard will be superior to the simple rule. ${ }^{93}$ At the enforcement stage, however, the complex standard will be more costly to employ. Thus, whether the simple rule or complex standard is superior depends on whether the benefits from the standard-which arise from its complexity-exceed the additional costs

90. For a discussion of the circumstances in which individuals would choose to become informed, see id.

91. Observe that it is plausible that a relatively simple rule would guide behavior more precisely than would a complex standard, as individuals might know all the modest content of the former but none of the potentially very detailed content of the latter. In this instance, the complex standard would be more over- and underinclusive with regard to its effect on behavior than the simple rule.

92. Because the legal regime imposes strict liability equal to harm actually caused, this adjustment in behavior will tend to be desirable, as explored in Section III(C).

93. This is the opposite of the result with case 3 in Part I. The reason is that, in the other case, individuals learned the content of the rule (but not of the standard) and conformed their behavior. Here, the simple rule has no content to guide behavior aside from what individuals already know, but the complex standard does and individuals learn its content. 
of the standard-which arise from both its complexity and its promulgation as a standard. ${ }^{94}$

Consider the case in which the latter scenario prevails (individuals learn of how the complex standard would apply to their conduct) and the balance of factors is such that the complex standard is more desirable than the simple rule. ${ }^{95}$ It still remains to ask whether the complex standard is more desirable than a complex rule-that is, one that determines in advance which chemicals are harmful. (Recall the hazardous substance illustration in Section B.) Such a complex rule would have higher promulgation costs than the complex standard, but lower advice costs and lower enforcement costs. This comparison between a complex rule and a complex standard is simply that between rules and standards, as presented in Part I. The components unique to the comparison between the simple rule and complex standard emphasized in this Section are those going to whether complexity is desirable. ${ }^{96}$ Study of this example thus reinforces the view that comparing simple rules and complex standards consists of two operations: analyzing complexity and analyzing the desirability of giving content to the law ex ante versus ex post.

\section{Are Standards Systematically More Complex in Application than Rules?}

Sections A through $\mathrm{C}$ described the analytic difference between the dimensions of the time (ex ante versus ex post) at which the law is given content and complexity. This final Section casts into doubt commonly expressed beliefs concerning the relationship between these two dimensions in practice.

94. If it were not complex, there would be nothing to determine ex post other than what is required to apply the posited simple rule; if it were not a standard, the cost would have been incurred (once) at the promulgation stage.

95. Of course, if the complex standard is less desirable, it is still important to ask whether a complex rule might be superior to the simple rule.

96. It is apparent from the discussion how one would compare a simple rule and a complex rule. But one could equally apply the discussion to standards, which, if simple, invoke the principle of average harm for the class of activity but, if complex, invoke the principle of harm for the particular activity in the class. (For example, standards of "reasonableness" often are applied in an "objective" manner that looks to typical characteristics of a group of actors rather than to particular characteristics of the actor in a given case.) 
Discussions often refer simply to rules and standards, indicating that the former tend to be over- and underinclusive. This characterization implicitly assumes that standards tend to be more complex than rules in the domains contemplated. This view may reflect that lawyers and legal academics are always able to imagine countless factors (arguments) that a decisionmaker might take into account if only it is permitted to do so. (Such imagining applies to rules as well, but standards are seen as allowing more room to maneuver.) This, however, is a romantic perspective, hardly a valid depiction of actual decisionmaking. ${ }^{97}$

As the Introduction noted, there are two fundamental problems with the assumption that standards inherently encompass more relevant considerations and thus achieve a better fit with underlying norms. First, standards need not admit all considerations. ${ }^{98}$ (In contrast, a rule may contain provisions that depend on factors that are not admissible under a standard.) Second, even standards that admit broader consideration ex post may not operate in a more precise manner, as illustrated by the example in the Introduction in which juries consistently make their decisions based on the same two or three of dozens of relevant factors. One suspects that if automobile design or workplace health and safety requirements were left to juries under a reasonableness standard, juries might tend to focus on a handful of factors that are most salient and easiest to comprehend.99 Thus, ignoring random error, the rule equivalent to the standard may depend on only a handful of factors and a simple weighting formula, nothing as complex as the analysis developed and the rules promulgated by auto safety regulators or OSHA. The same can be said with regard to the federal income tax, as noted in the Introduction. ${ }^{100}$

97. Some commentators emphasize that standards cannot simply be assumed to function without error. See Schauer, supra note 4, at 685-86 (decisionmakers unconstrained by rules will err, and this risk of error need not be less than that which would arise from faithful application of over- and underinclusive rules).

98. Cf. id. at 648 n.6 (distinguishing the case in which the decisionmaker consults a single background justification for a rule from that in which all possible justificatory norms may be considered).

99. Also, over time jury instructions may be developed that limit juries' focus. See supra note 14. Such instructions might be analogized to precedents (a form of rules), discussed in Section I(C) and subsection IV(B)(1).

100. An example that might be more familiar to many readers of this Article is the determination of financial aid. If financial aid is determined based on "need, all things considered," one might expect that case-by-case judgments would, in practice, ignore 
There is a simple explanation, explored in Section I(D), for the fact that rule systems are often complex compared to the results that actually would arise under standards. Case-by-case creations (and re-creations) of complex formulas are expensive. When one economizes on that process, recognizing that the formula is to be used only once, it is sensible to oversimplify greatly, and thus to consider only the factors most likely to be important. When one makes a single pronouncement that will govern many (perhaps millions) of cases, it is worthwhile to undertake greater investigation into the relevance of additional factors and to expend more effort fine-tuning the weight accorded to each. Thus, when rules are to be applicable to frequent behavior with recurring characteristics, there is a systematic tendency for rule systems to be more complex than the content that would actually be given to standards covering the same activity. In contrast, when the behavior to be regulated by law is infrequent, or when each instance (no one very likely to occur) is unique in important ways, substantial ex ante analysis for each conceivable contingency would be a poor investment, whereas ex post determinations under standards are made with the knowledge that the scenario has indeed arisen. As emphasized in Part I, frequency is a central consideration determining the relative desirability of rules and standards. Here, we see that it is similarly relevant when considering the costs of employing more complex laws. ${ }^{101}$

many subtleties, overstating need in one case (because, for example, nontaxable sources of income are overlooked) and understating need in another case (because, for example, insufficient attention is given to how parents' other dependents dilute the parents' ability to pay). A complex rule scheme that is applied rather mechanically (at far less cost per case) may be much less over- and underinclusive than such case-by-case judgments would be.

101. There is also an important synergy between complexity and the choice of rules and standards (which implies that the optimal rule and optimal standard may differ in content). The degree of complexity affects frequency, in the sense used in this Article. See infra Section III(B). Consider the following example. There are 100 possible acts subject to a law, each with a $10 \%$ chance of ever arising. If complexity is of little value (that is, if the acts are rather similar, so little is lost by treating them identically), a rule may be cheaper: The promulgation cost differential is borne only once while the costs of interpretation by individuals and enforcers are expected to be borne 10 times $(10 \% \mathrm{X}$ 100 ). In contrast, if complexity is of great value and each of the 100 acts is really quite different, calling for different legal treatments, a standard may be cheaper: With a rule, 100 decisions must be made, whereas with a standard individuals and enforcers need only address the 10 acts that actually arise. This suggests that when complexity is important, frequency in the relevant sense will be less. Of course, if frequency is still sufficiently great, the relative benefit of rules may be even greater when complexity is important. 
It is curious, therefore, that most commentators assume that standards tend to be complex in operation compared to the rules that might replace them, with little effort devoted to comparing standards that are simplistic in application with complex rule systems. ${ }^{102}$ The main point to recognize is that there is no universal tendency for standards as they are actually applied to be more complex than rules that would plausibly be promulgated. ${ }^{103}$ Thus, subsuming the benefits of complexity under the banner of standards or those of simplicity under the banner of rules not only obscures the analysis, as suggested in Section B, but does not correspond very well to the legal universe.

\section{EXTENSIONS}

\section{A. The Accessibility of Rules and Standards}

In Part I, it was suggested that individuals will find it cheaper to learn how rules would apply to their circumstances than to learn how standards would apply, because the former will have already been given content whereas the latter will require predicting the content that a later decisionmaker will provide. As a result, rules tend to be preferable with regard to individual behavior, because individuals will expend fewer resources learning about the law and will learn more under rules and thus behave more in accordance with the law. If, instead, it were cheaper to learn about standards, these aspects of the argument would be reversed. This Section considers the plausibility of the view that standards, rather than rules, would typically be more accessible. Ultimately, of

First, because the cost of learning about rules is less, it is more likely that behavior will reflect the law (which is more important when there are important differences among individuals' acts that the law takes into account). Second, there may be economies of scale in making the inquiries at the promulgation stage: Determining the appropriate treatment for each of the 100 possible acts may cost little more than for one act (because the same investigation may yield most of the relevant information). In that case, a rule would entail bearing the investigation cost-which may be unusually large with complex phenomena-once while the standard may require that it be borne 10 times in enforcement proceedings (and, possibly, additional times when individuals act).

102. Perhaps the bias arises because prior authors have been more familiar with laws such as the negligence rule for automobile accidents than with public regulatory regimes.

103. The question is meaningful only if one is considering a particular legal context-i.e., whether traffic laws should be formulated as rules or standards-rather than comparing the complexity of a rule in one area of law to that of a standard in another. 
course, the question is empirical; whatever the correct answer is in a given context, the general framework of Part I could be applied.

In some instances, it might appear that a standard would be easier for individuals to apply because some cases will be obvious under the standard, whereas if the rule is complex, it may take some effort to verify that no exception applies. This construct implicitly assumes that, under a standard, modest effort would yield a rather confident (but probably not perfectly certain) prediction, whereas under a rule, either substantial effort would be expended to yield nearly complete certainty or little effort would be applied, leaving the individual with little idea of the governing law. But in most instances, these assumptions are inconsistent: The likely (if not certain) result will often be just as obvious under the complex rule as under the standard. For example, under a standard requiring safe driving, most drivers would readily anticipate that driving at night without headlights illuminated or parking in the middle of an intersection would be proscribed. At the same time, much unsafe driving behavior is currently prohibited by specific traffic regulations, most of which drivers have probably never read; surely, such drivers have no difficulty guessing, with high confidence, what these unseen rules require in most instances.

Individuals subject to a complex rule system will only make additional expenditures, to achieve higher confidence in their predictions, if the perceived value exceeds the perceived cost. But this can be true only if individuals are in fact materially uncertain about what the rules would say about their contemplated conduct. ${ }^{104}$ For example, drivers of trucks that transport dangerous substances might check which roads or bridges are closed to such traffic. In precisely such instances, however, drivers probably will be uncertain about what content would be given to a standard that limited driving to "appropriate" routes. ${ }^{105}$ And, if legal advice is

104. Cf. SCHAUER, supra note 1 , at 139 (rules enhance predictability when actors cannot otherwise predict how an adjudicator would resolve the case because actors and adjudicators do not have common outlooks, but they do share common language).

105. Recall that the comparisons thus far deal with rules and standards that would have the same content if the same effort were applied in giving each content-that is, where the process producing the rule considers the same factors, giving them the same weight, as the process that will later give content to the standard.

A qualification arises when, because of the frequency of potential application, greater effort would be expended ex ante in designing a rule than ex post in applying a standard. In that case, there may be detailed distinctions made in the rule that would not be made in applying a standard. (This is precisely the instance noted in Section II(D), in 
to be obtained in such a case, one would expect, as before, that rules could usually be predicted at lower cost than standards, precisely because more content has been provided in advance. Thus, with the rule, one would perhaps simply consult an official map. In contrast, under the standard, it would be necessary to ascertain the weight given to various factors by adjudicators and the actual circumstances of each route (such as population density, presence of groundwater, and the like).

The possibility that standards will be more accessible to individuals than rules might be rationalized on account of the differences in the institutions that give content to each. ${ }^{106}$ The implicit scenario is one in which a legal command, if promulgated as a rule, will be given technical detail by lawyers or other relevant experts-whereas standards will be given content through decisions of lay juries, who will rely on common understandings (rather than on, say, expert testimony) ${ }^{107}$ For the argument to work, it must further be assumed that the content given to standards by lay decisionmakers will diverge significantly from the content that experts would choose to give to rules. Otherwise, individuals guided by common understandings would be equally able to comply with the technical rules, as the preceding discussion explains.

This version of the argument has important shortcomings. First, these implicitly assumed features of rules and standards would involve choices that could be made differently. For example, if lay content were preferred for reasons of accessibility, but rules were preferred to avoid costs of repeated ex post decisionmaking, one could assemble a lay panel to design rules, just as expert

which rules are more complex than standards, as applied.) To the extent individuals subject to the more complex rule would not in fact expend the resources necessary to learn and thus adjust their behavior to the additional detail (or if the expenditures in learning the detail were not socially warranted), it would not be optimal ex ante to design so detailed a rule. This is the analysis of complexity, presented briefly in Section $\mathrm{II}(\mathrm{C})$, which was there distinguished from the issue of the appropriateness of giving content to the law ex ante versus ex post.

106. Institutional differences are considered further in Section IV(A).

107. See, e.g., POSNER, supra note 1 , at 47-48. Other institutional considerations suggest that rules might be more accessible to individuals. Representative legislative bodies or administrators subject to political pressure may be easier to predict than juries or other adjudicators, because of possible idiosyncrasies of the latter-concerning the decisionmakers themselves or the information that they will be given in a particular case-and their being subject to different influences. 
testimony is used in adjudication when society wishes standards to be given content in a manner that incorporates relevant expertise.

Second, if experts would otherwise be appropriate when rules are promulgated, it must be because the content they will give to rules is superior to the differing content that would be supplied by lay decisionmakers ex post. This suggests that if standards would achieve greater conformity, the conformity is with commonly made mistakes rather than with underlying norms. (If the experts' results are indeed no better, but just different, then the accessibility argument disfavors relying on experts, not ex ante creation of the law.)

Finally, the scenario usually imagines that individuals will not seek advice to guide their behavior, which is plausible for the everyday activity of individuals that is unlikely to have significant legal consequences, but not for many other activities governed by legal commands. If expertise is indeed helpful in designing the law, and if the resulting law does differ importantly from lay understandings, then the tendency of technical rules to induce individuals to seek advice would be desirable. For example, suppose that in a regime covered by a standard that simply required appropriate disposal, most individuals dump most chemicals down the drain because they suspect a lay jury would find this action appropriate (from the point of view of unsophisticated actors, like themselves). Then, substituting detailed rules, indicating appropriate methods of disposal for those chemicals that are hazardous, may be helpful, as these individuals might then fear that they would be in violation of the law and be induced to seek advice before acting. ${ }^{108}$

\section{B. The Difficulty of Formulating Some Laws as Rules}

It would appear that some legal commands cannot plausibly be formulated as rules. For example, it may not be possible to

108. Observe that a similar result might follow if individuals knew that their liability would be adjudicated by experts, or by a lay jury instructed that the standard requires individuals to take technologically appropriate action and informed by the testimony of experts on the subject. This highlights the first point, that the desirability of expertise rather than lay instinct is, in principle, substantially separable from that of the choice between rules and standards. In practice, there may be an important connection for the reasons described in Section I(D): If a rule is to apply to many individuals' behavior, additional investment in design might be appropriate (so it might be worth investing substantially in expertise) compared to the situation employing standards. Or, if a circumstance is unlikely to arise, ex ante investment in expertise may not be warranted but, once the situation has arisen, it may be worthwhile to consult experts. 
specify in a zoning ordinance which building designs are aesthetically inappropriate, but we may know them when we see them. Or we may be unable to specify in advance proper disposal techniques for all hazardous substances because we cannot foresee all potential hazards-whereas some hazards, and how best to address them, may become apparent when they arise.

Because of such factors, rules may seem not only to be inferior to standards, but an entirely infeasible option. Such limitations of rules, however, are already incorporated into the analysis. In particular, they are largely reflected in the frequency dimension emphasized in Part I, and also in the discussion of promulgation versus enforcement costs in Section I(D). ${ }^{109}$ For example, the problem with building designs is that the possible permutations are many. The cost of making an advance ruling on millions of possibilities would be excessive, as few would ever arise in any event. It is not the case, however, that nothing can profitably be determined in advance. Size (square feet, height), building materials, distance from the street, and other characteristics could be articulated, leaving to some adjudicator the task of undertaking further review of submitted plans.

The choice between rules and standards is one of degree. Deciding solely on the relevant criteria in advance may save costs for both individual actors and adjudicators, while providing individuals some guidance. Also, adopting presumptions or ruling certain options in or out might be possible. The extent to which such approaches are desirable will depend on the anticipated frequency of behavior with the relevant common elements. The commonality aspect is worth emphasizing when defining frequency for the purposes of this Article. The law of negligence may cover millions of acts, but if most types have little in common with each other and are unlikely to arise, behavior at the relevant degree of detail is infrequent. ${ }^{110}$ But if some particular type of act will arise even a dozen times, that may be sufficiently frequent to warrant an $e x$ ante wholesale resolution of the problem.

Yet another limitation on the ability to formulate laws as rules involves limitations of language. Even if there is precise

109. The discussion in this section emphasizes frequency. The added cost of designing rules when events are difficult to anticipate is discussed in note 78 .

110. This discussion highlights a synergy between the issue of complexity and the issue of when laws should be given content, as discussed in Part II. See supra note 101. 
consensus on the meaning of, say, "vulgar behavior," it may be difficult to describe the set of behavior precisely and succinctly. As with the example involving aesthetic zoning, the problem may involve frequency, as the range of vulgar behavior is substantial.

If, however, the problem is simply that readily identifiable and recurring behavior is difficult to describe, using a rule may pose no difficulty with regard to the issues addressed in this Article. The rule could simply prohibit "vulgar behavior." As long as the relevant audience took this to refer to a familiar set of acts, an ex ante specification would have been made in the relevant sense. ${ }^{111}$ That is, whether a law has been given content ex ante depends on whether information acquisition and processing that might require effort has been completed ${ }^{112}$ not on the type of language that best communicates the results of ex ante investigation and decisionmaking. ${ }^{113}$ This Article has focused on the division of effort over time: A legal command is defined here to be rule-like to the extent that greater effort has been expended ex ante, rather than requiring such effort to be made ex post. ${ }^{114}$ Thus, for a legal command prohibiting vulgar behavior to be viewed as a standard for present purposes, it would have to be understood that the command authorizes the adjudicator to make a de novo inquiry into what constitutes vulgar behavior, for only then would application of the standard be costly and difficult for individuals to predict. To the extent the domain of vulgar behavior would have been well understood, the decision to prohibit this category of activity, but not other activity raising similar concerns, should be seen as a rule. ${ }^{115}$

111. $: \rightarrow$ Frederick Schauer, Formalism, 97 YALE L.J. 509, 512 n.8 (1988) (using the broadly worded university honor codes of the eighteenth and nineteenth centuries as an example of commonly understood precepts).

112. After all, even a precise rule-one prohibiting driving in excess of 55 miles per hour-requires some effort to interpret.

113. See supra Section I(E); infra subsection IV(B)(3); cf. ATIYAH \& SUMMERS, supra note 1, at 81-83 (instances in which English laws appear less rule-like than American laws may still entail a more formal, predictable approach in England because of its more developed customary norms arising from the greater homogeneity of the British people and English judiciary); Sanford Levinson, Some Reflections on the Posnerian Constitution, 56 GEO. WASH. L. REV. 39, $40 \mathrm{n} .2$ (1987) (what may appear to an outsider as a rule might be understood by an insider as a standard, or vice versa).

114. See supra subsection I(A)(1) (emphasizing that the motivation for the problem is that the ideal content of the law is not immediately apparent); Section I(E).

115. A related limitation on formulating laws as rules may involve the reluctance to 


\section{The Private Versus Social Value of Legal Advice}

Whenever individuals acquire legal advice, the question arises whether their decisions to do so are socially desirable. Answering this question involves comparing the effect of advice on behavior with the cost of advice. In subsection I(B)(3)-analyzing the case in which individuals would acquire advice under a rule but not under a standard-it was noted that the overall effect of obtaining advice is necessarily desirable if the private value of advice equals the social value of advice. ${ }^{116}$ The reason for this result is that individuals only acquire advice when its private value exceeds its cost; so in this case, it must be that the social benefit of advice exceeds its cost.

In addition, the discussion in Section I(D) emphasized that individuals' decisions to acquire advice are a matter of degree. Individuals may, for example, choose to become more informed about rules because the cost of advice is cheaper. In such instances, their total expenditure on advice may be greater under rules or under standards. (Under standards, even when less advice is acquired, the cost for a given amount of advice is greater, so the total cost may be greater.) If expenditures are greater under standards, but individuals are more informed under rules-and more informed individuals act more in accord with underlying norms-the net effect of advice at this stage would tend to favor

draft precise legal commands except in simple "on/off" forms or as expressing linear relationships. For example, suppose that the ideal formula for the level of care depended on the variables $x$ and $y$, so that there should be liability if and only if $x^{2} y$ exceeds some particular level. After hearing (possibly expert) testimony, a factfinder might (approximately) reach correct conclusions under a standard. A rule could substitute if it indeed provided for liability as a function of the stated condition. But if the rule drafter were limited to having separate on/off tests for $x$ and $y$, or possibly allowing $x$ and $y$ to be added, the best rule may lead to many poor results. Judgments of factfinders often may reflect (roughly) complex interactions of variables that we tend not to write in rules (except perhaps in the tax law and some other complex statutory or regulatory schemes). Related, judicial precedents and jury instructions tend toward simple formulations; when these are found unsatisfactory, multiple factor tests or commands to consider all the facts and circumstances are promulgated, often with little further guidance. See infra note 155. The option of a rule specifying a complex interaction does not usually receive serious attention. See gener $\rightarrow$ Søren Bisgaard, Design of Standards and Regulations, 154 J. RoYAL STAT. SOC'Y 93 (1991) (ambiguity can often be reduced using statistical methods and concepts when laws are designed); Ogus, supra note 1 (discussing dichotomy between general and complex, precise rules, and the recent trend in judicial preference for generality).

116. See also supra note 44 (discussing the possibility that the private value of advice is greater than or less than its social value). 
rules. ${ }^{117}$ Determining whether the net effect at this stage favors rules or standards in other situations and quantifying the net effect requires that one examine the relationship between the private and social values of legal advice. Observe that if the private and social values of advice are equal, then whatever level of advice individuals acquire will be socially appropriate, producing benefits of advice in excess of the cost of advice-taking as given whether a rule or standard prevails. Moreover, to the extent the cost of advice is lower under rules than under standards, rules will necessarily be preferable on account of this factor. ${ }^{118}$

The subject of the social value of legal advice deserves and has received separate treatment. ${ }^{119}$ A few themes will be noted here. First, there is an important instance in which the private and social values of advice will be equal: when individuals will be held liable for the full costs of any harm they cause. ${ }^{120}$ Because an individual bears all the consequences of each act, it follows that advice guiding the choice among acts will have a value to the individual that reflects its social value. ${ }^{121}$ Second, to the extent that the legal system does not provide liability equal to the actual harm of acts, there generally will be divergences between the private and social values of legal advice. ${ }^{122}$ For example, under some circumstances the private value of advice will be socially excessive under a negligence rule, because individuals value escap-

117. Advice at this stage may affect total costs at the enforcement stage, because advice may affect the number of lawsuits that later occur. An optimal law of damages would take into account both the direct harm caused by acts and the enforcement costs, which can have the effect of internalizing this cost at the time individuals decide whether to acquire legal advice and how to act. See KAPLOW, supra note 89, at 8-9; see also A. Mitchell Polinsky \& Steven Shavell, Enforcement Costs and the Optimal Probability and Magnitude of Fines, 35 J.L. \& ECON. 133 (1992). If enforcement costs were thus internalized, individuals' decisions concerning the acquisition of information and level of care would be optimal. (Promulgation costs are sunk at the time individuals' decisions are made.) If there is an external effect on enforcement costs, it is not clear that it would tend to favor more or less advice, as advice may lead individuals to take actions that would result in fewer or more subsequent lawsuits. See supra note 41.

118. When social value is reflected in private demand, a reduction in the resource cost of supplying a good or service-here, legal advice-is desirable.

119. $\rightarrow$ Louis Kaplow \& Steven Shavell, Private Versus Socially Optimal Provision of Ex Ante Legal Advice, 8 J.L. ECON. \& ORGANIZATION 306 (1992).

120. See also supra note 117 (discussing subsequent enforcement costs as a component of the harm of an individual's act).

121. For a formal demonstration, $\rightarrow$ Kaplow \& Shavell, supra note 119, at 308-09.

122. The examples that follow and others are analyzed in id. at 309-16. 
ing liability entirely when they take due care, despite the fact that they nonetheless cause harm. ${ }^{123}$ Third, to the extent there is legal error (for example, systematic misassessment of damages) that individuals can better anticipate with the aid of legal advice, the private value of advice may be socially excessive. ${ }^{124}$ Moreover, in this instance, advice tends to be socially undesirable even without regard to its cost, because advice leads individuals to behave less in accord with underlying norms. ${ }^{125}$

If one adopts the view common (if often implicit) in discussions of rules and standards that greater knowledge of the law by individuals subject to it is desirable, the tendency for individuals to be more knowledgeable of rules because of the lower cost of advice about them would favor rules. Recognizing that the private and social values of advice need not be equal complicates the argument. Divergences between the private and social values of

123. The text speaks of a negligence rule, a term most commonly used in describing accident law. The concept, however, is more general. Any law in which liability only arises when care is unreasonable in some respect is a negligence regime for present purposes. See id. at 317. For further discussion of behavior when there is uncertainty regarding application of the negligence rule, see supra note 42 .

124. The mere existence of error is not sufficient, as long as individuals (even with legal advice) expect the law to be applied properly, or if individuals do not expect there to be systematic biases in what enforcement tribunals will award.

125. The possibility that predictable legal error will lead to worse behavior might in some contexts favor standards over rules for the very reason that individuals will be unaware of the content of standards whereas they would become informed about rules. The scenario is as follows. Individuals know the true character of their acts (as they would be evaluated by an omniscient social authority), but the government-when promulgating rules or applying standards-cannot determine their true character. Rather, it makes random errors. If these errors will be made under a standard-and thus after individuals decide how to act-the actual error with regard to a particular type of behavior cannot be precisely predicted. But if an ex ante determination of the appropriate treatment of a particular act is made, any error will be knowable before individuals act, so it may lead them to act in an undesirable manner. This example illustrates how advice about error-whether error embodied in a rule or the prediction of error likely to be made in applying a standard-can be socially undesirable. It also suggests that errors under standards will be important with regard to behavior only to the extent individuals can anticipate the errors at the time they act, perhaps when aided by legal advice. But see supra note 42 (mere uncertainty under a negligence rule may adversely affect behavior). To the extent error will be anticipated, greater expenditures on ex post accuracy would be warranted. (This problem also creates a rationale for making errors difficult to predict-for example, by forbidding contact with jurors when interviews might reveal bases for decision unrelated to the underlying legal norms.) As noted in subsection I(D)(3), if behavior is frequent, greater investment in giving content to rules than to standards would be appropriate. This suggests that the problem of error may be greater under standards. 
advice could favor either formulation relative to the balance of factors that otherwise would prevail.

\section{Risk Aversion}

Risk aversion is relevant to the analysis of rules and standards for two reasons. ${ }^{126}$ First, individuals' behavior will reflect their risk preferences. The most important implication is that individuals will place a greater value on legal advice because advice reduces their uncertainty. ${ }^{127}$ This suggests that it may be more valuable than otherwise for the cost of legal advice to be low, a factor favoring rules.

Second, when individuals are risk averse, their bearing of risk is socially undesirable. Because individuals tend to be less well informed concerning standards, they may bear more risk under standards, which would favor rules. Another consideration is that the precision with which laws are actually applied may affect the risk individuals bear. (For example, to the extent liability is designed to compensate uninsured victims, it is important that the compensation reflect actual losses.) This factor may favor standards, to the extent they can better take advantage of information available only ex post, or it may favor rules if less is invested in applying standards (because the investment will apply to only one case). ${ }^{128}$

126. Risk aversion is also relevant to Part II's discussion of complexity. More complex rules, which some individuals will not learn, might result in more risk being imposed. (Whether more risk is indeed imposed is formally ambiguous. See KAPLOW, supra note 89.) If more risk were imposed, simpler (and, as a result, more over- or underinclusive) laws-whether rules or standards-would tend to be favored.

127. This additional private value of advice is also a social value, because risk-bearing costs are social costs. Thus, the presence of risk aversion has no direct effect on whether there will be a divergence between the private and social values of legal advice, as discussed in Section C.

128. The appropriate investment in designing rules and applying standards may be determined in part by considerations of accurate compensation, in addition to the ability of the law to influence behavior, which has been the focus throughout. This might favor greater effort in giving content to the law (to fine-tune victim compensation) or less (because individuals will not be fully informed at the time they act or because the actual harm to a particular, unidentified victim cannot be predicted, so that fine-tuning ex post entails greater risk ex ante for those committing acts). See KAPLOW \& SHAVELL, supra note 51 , at $18-19$. 


\section{E. Objectives of the Law Other than Deterrence}

The analysis thus far has focused on the purpose and effect of law with regard to controlling behavior ex ante. ${ }^{129}$ Individuals who anticipate the possibility of sanctions will adjust their behavior accordingly. This Section briefly notes the extent to which the analysis is applicable to other objectives of the law. The relevant objectives often depend on the nature of the sanction and on the type of legal proceeding.

The law uses not only monetary sanctions but also specific relief, such as injunctions in the civil context ${ }^{130}$ and the incarceration of criminals. The anticipation of such nonmonetary sanctions obviously influences behavior $e x$ ante, and to that extent the previous analysis is applicable. Because there are also ex post effects on behavior, however, the value of precision at the enforcement stage is greater than it otherwise would be. Thus, if extremely harmful activities are to be permanently enjoined or dangerous individuals are to be removed from society, it is valuable to invest resources to make accurate determinations in adjudication even if the enhanced accuracy does not affect ex ante behavior (because individuals would not invest in legal advice to a sufficient extent to refine their predictions). This favors both greater effort in designing rules and in giving content to standards. ${ }^{131}$ And, whichever formulation results in a more accurate resolution of specific cases will tend to be favored. ${ }^{132}$

129. An exception is the argument in Section D that the outcome of enforcement proceedings will affect the extent to which actors and victims bear risk.

130. The effect of injunctions depends on how enforcement and bargaining actually operate. For example, if an injured party would negotiate for a payment in lieu of pursuing injunctive relief, the effect may be the same for present purposes as if the law provided for damages of that amount.

An important form of injunctive relief in which future conduct is a primary consideration is licensing. See, $e \rightarrow$ Diver, supra note 1 , at 79 .

131. Considerations of $e x$ post effects of laws are relevant when evaluating the law/equity distinction that was basic to Anglo-American law until developments in this century led to the currently often-held view that the distinction serves no social function. Because equitable remedies are nonmonetary, the appropriate proceeding for determining their application and the optimal content of governing legal commands is different from that for remedies at law-damages. Whether actual differences in legal and equitable proceedings historically or presently reflect this concern is another matter.

132. As noted previously, standards may provide more accurate resolutions because of information made available ex post, or less accurate resolutions because it is appropriate to invest less effort when the investment will be used in a single adjudication rather than in a rule that would apply to many cases and because economies of scale possible at the 
Even when the law provides purely monetary relief, there may be objectives in addition to deterrence. As explored in the preceding Section, the compensation victims receive and the amounts injurers pay will be independently significant when individuals are risk averse. Accuracy of results will be of greater importance because it is desirable that victim compensation reflects actual losses, ${ }^{133}$ while greater accuracy ex post is not obviously valuable for injurers. ${ }^{134}$ As a related matter, some laws involve government transfers, such as Social Security payments to disabled workers. Here, accuracy is relevant primarily with regard to providing correct compensation. ${ }^{135}$

In addition to affecting future behavior and the ability of the legal system to achieve compensatory objectives, accurate outcomes may be viewed as an important determinant of the fairness of the legal system. If so, greater investment in the promulgation and application of laws may be warranted than otherwise and there would be an additional reason to prefer whichever mode of formulation tends to produce greater accuracy. Regardless of the weight generally thought appropriate to such fairness concerns, note that accuracy in the present context has an important characteristic distinguishing it from many others: Individuals may not anticipate the results. Recall that accuracy will not always influence $e x$ ante behavior precisely because the ultimate application of laws may be too difficult to predict. ${ }^{136}$ Even when standards provide more ac-

rule promulgation stage may be unavailable when standards are applied. See supra Section I(D); note 101; see also supra Section II(D) (rule systems may be more detailed than standards as actually applied).

133. To the extent compensation is motivated by risk aversion, monetary losses (with a possible adjustment for changes in the marginal value of money caused by the injury) rather than total losses would be relevant. See SHAVELL, supra note 42, at 228-31, 245-47.

134. Greater fine-tuning of damages to actual losses may increase the risk injurers bear without materially affecting their behavior. (Greater risk will deter, but the additional deterrence may be excessive and, if it is desirable, could be achieved, say, by increasing damages.)

135. The context of welfare payments is perhaps that in which accuracy has been most discussed, provoked by the Supreme Court's decision in Mathews v. Eldridge, 424 U.S. 319 (1976). See, $e \rightarrow$ Jerry L. Mashaw, The Supreme Court's Due Process Calculus for Administrative Adjudication in Mathews v. Eldridge: Three Factors in Search of a Theory of Value, 44 U. CHI. L. REV. 28 (1976). The extent to which such determinations are to be governed by rules is one important element determining the ultimate accuracy of outcomes. See, $e \rightarrow$ Diver, supra note 1 , at 88-92. See generally JERRY L. MASHAW, Bureaucratic Justice: Managing Social Security Disability Claims (1983).

136. $\rightarrow$ Louis Kaplow \& Steven Shavell, Legal Advice About Information to Present 
curate resolutions of particular cases, individuals may not have effective notice of the result an adjudicator would reach and thus would be unable to act in light of it. Thus, even when rules will be less accurate in providing results that are appropriate to actual circumstances-which they often will not be ${ }^{137}$ - they will tend to provide clearer notice than standards to individuals at the time they decide how to act. ${ }^{138}$

\section{FURTHER CONSIDERATIONS}

This Part comments on additional issues relevant in comparing rules and standards. There is no attempt to be exhaustive or to analyze the issues in depth. (Many have been discussed elsewhere and most warrant further study.) Rather, the purpose is simply to note important factors that are related to the discussion in the preceding Parts.

\section{A. Promulgation and Enforcement of Law by Different Govern- ment Institutions}

The discussion thus far has suggested that the costs of promulgating and applying laws may differ for rules and standards. Reasons for such a difference that arise because rules are given content $e x$ ante and standards $e x$ post have been emphasized. Another reason that promulgation and enforcement costs, as well as the content of rules and standards, may differ is that different government institutions may be involved at the two stages.

Beginning with the most commonly assumed context, consider some of the differences between legislatures, which promulgate many laws, and courts, which often apply them. Legislatures may be better equipped to draw upon technical expertise than courts. Also, through the use of committees and staffs, legislatures may develop more expertise of their own. On the other hand, legisla-

in Litigation: Its Effects and Social Desirability, 102 HARV. L. REV. 565, 603 (1989) (discussing how legal advice in litigation may not align sanctions with individuals' ex ante understanding of the law because such advice affects sanctions in a manner individuals cannot anticipate).

137. See supra note 132 (factors determining whether rules or standards would be more accurate).

138. This may be more fair, as individuals are more able to comply with the actual content of the law, and more desirable in terms of the law's purposes to the extent that substantial compliance with imperfect rules yields better results than poor compliance with more nearly perfect standards. 
tive agreement may be more difficult to achieve given the numbers of decisionmakers and the division of authority. ${ }^{139}$ Courts, for better or worse, tend to rely on adversary proceedings in reaching conclusions. Also, courts tend to be driven by the concrete facts of a particular case, which may simplify judgment (one need not rely on imagination to anticipate contingencies) or may mislead the decisionmaker (as when the vividness of the instant case leads one to underemphasize other cases that might be subject to the same law ${ }^{140}$ or when hindsight is not understood to be superior to foresight). Legislatures may be more politically responsive, which might make some value judgments more legitimate (because they are more representative of popular will) or more suspect (because they reflect the influence of unrepresentative interest groups). ${ }^{141}$ Rules may be preferred to standards in order to limit discretion, thereby minimizing abuses of power..$^{142}$ Legislatures and courts may each be more sensitive to costs that they directly incur than to costs incurred by other institutions or by individuals, which may induce them to prefer an otherwise inappropriate formulation. ${ }^{143}$

139. See, $e \rightarrow$ Ehrlich \& Posner, supra note 1 , at 267-68.

140. This problem is particularly important if a precedent is to be created. Related, relevant "legislative facts" may not be formally admissible in a particular controversy. This consideration is an important reason that judges are inclined to favor waiting before announcing precedents, formulating narrow ones, or simply deferring to the legislature. See infra subsection $\mathrm{B}(1)$; see also supra subsection $\mathrm{I}(\mathrm{D})(3)$ (when adjudication will govern only one case rather than many, it may be sensible to make a more superficial inquiry).

141. Concerning the latter, the content of a law or the mode of formulation may be designed to serve a well-organized group to the disadvantage of most citizens. Alternatively, a legislature may delegate authority (to agencies, as when it creates a commission and empowers it to promulgate regulations, or to courts, as when it enacts a standard) not because it deems delegation optimal in principle but because it wishes to avoid accountability. See, $e \rightarrow$ Diver, supra note 1 , at 106 . Related, the discussion in subsection B(1) of courts' reluctance to establish precedents could reflect either a view as to what is proper or a desire to avoid taking responsibility.

142. See, e.g., DAVIS, supra note 1; POSNER, supra note 1, at 44; SCHAUER, supra note 1 , at 150-51, 158-62; Gavison, supra note 4, at 753-54. That is, it may be feared that courts, agencies, or other political actors will provide content to standards in improper ways. In contrast, if they were empowered simply to apply rules there would be less potential for such abuse because improper conduct could be more readily detected. See, e.g., SCHAUER, supra note 1, at 150-55. Cf. RAZ, supra note 5, at 59-60 (rules may reduce risk of error because content is determined in time of tranquillity).

143. For example, legislatures may favor standards because the ex post costs are incurred by individuals and courts. (Often when legislatures fail to resolve an obvious ambiguity that ultimately will be resolved by courts establishing a rule-as in the failure to state a statute of limitations-one suspects that time pressures, a desire to transfer costs, 
And the difficulty of learning about laws promulgated by legislatures may differ from those promulgated by courts (as when content is given to a standard through precedent) because of the manner in which legislative enactments and judicial opinions are written, published, and indexed. ${ }^{144}$

An important caveat in considering these factors is that many are not inherent to the institution, but rather reflect particular choices that have been made. For example, courts could be specialized (as some, such as the tax court, are) or have expert staffs. Judges could be selected differently so that they would tend to be responsive to different forces. ${ }^{145}$ Precedents could be established in a more rule-like fashion than is usually done. (Examples of such an approach include Miranda ${ }^{146}$ and Roe $v$. Wade. ${ }^{147}$ ) On the other hand, some differences are intrinsic to the central question of this Article: whether the law is given content ex ante or ex post. Most notably, standards allow a decisionmaker to examine the concrete facts of a particular case. ${ }^{148}$

or a simple mistake is the explanation, rather than some intrinsic reason that a standard is preferable. See Maggs, supra note 47 , at $142-51$ (documenting and examining twenty recurring ambiguities in the drafting of statutes).) Courts, in turn, may favor rules to the extent that they reduce the courts' own future costs, or standards, because they save promulgation costs while many subsequent costs are borne by private parties (or different judges in future cases). Some agencies will be the adjudicators under their own laws, whether standards or rules, so they bear all the costs at stages one and three, although costs to individuals (stage two) are still external to them.

The choice of rules over standards also tends to reduce the costs borne by private parties. One implication is that lawsuits may be less costly, encouraging more potential plaintiffs to file. See supra note 35 . Of course, public costs could be charged to private parties and private costs could be subsidized, so the incidence of costs is not an inherent feature of whether rules or standards govern. (Who bears costs may be relevant for incentive purposes aside from the effect on the likelihood of suits. For example, those developing new drugs must bear many of the costs of tests that are submitted to the government in determining whether to permit their sale; in this manner, the drug companies bear the full cost of their products.)

144. See supra note 47 ; see also infra note 162 (how prior judicial opinions guide a judicial decision).

145. There is in fact important variation in how judges are selected in different states (various forms of election and appointment) and across countries (for example, the use of career judiciaries, with various structures for promotion and retention).

146. Miranda v. Arizona, 384 U.S. 436 (1966).

147. 410 U.S. 113 (1973).

148. This difference, however, is less important than may first appear. A standard may be applied with the guidance of general studies of a problem and a rule may be designed with reference to a single occurrence that has been observed. Still, as described in subsection I(D)(3), standards have the advantage of access to concrete facts that may not have existed when a rule was created. Relatedly and more broadly, how rules and stan- 
It should also be emphasized that the institutional possibilities are more varied than is suggested by the typical focus on legislatures and courts. First, rules are promulgated by all three branches of government. In addition to legislatures, courts create rules through precedents and executive agencies promulgate regulations and enforcement guidelines. Second, standards can be applied by many agents. Executive officials-often prosecutors-exercise prosecutorial discretion. Legislatures can override particular decisions and enact private legislation. And, within courts and other adjudicative bodies, standards can be interpreted by judges, juries, experts, or arbitrators. ${ }^{149}$

A consequence of these latter remarks is that many issues concerning the separation of powers, the operation of legislatures and government agencies, the exercise of prosecutorial power, and the rules of civil and criminal procedure, are importantly intertwined with the question of how a legal system can best give content to the law. Thus, in addition to asking whether a law should be promulgated as a rule or a standard, taking the institutional context as given, the present analysis is relevant to analyzing the reform of legal institutions. At a narrower level, an institution contemplating the enactment of a law may have choices as to which institutions (including itself) will design and apply the law.

\section{B. Precedent and Predictability}

Much of the analysis has been concerned with the ability of individuals and lawyers to predict the application of the law and of adjudicators to apply it. To the extent laws are promulgated as standards, predictability will be enhanced by precedent to the extent precedent transforms standards into rules. ${ }^{150}$ This Section

dards are optimally designed and applied is influenced by their inherent difference with respect to timing, as discussed throughout Section I(D).

149. One effect of the choice of adjudicators concerns the predictability of their decisions by individuals and lawyers. One might suspect, for example, that juries (allegedly of one's peers) or arbitrators (if, for example, they are from the same industry as the actors) may be more predictable by individuals (without the aid of legal advice) than judges are. On the other hand, judges may be easier for lawyers to predict, which would tend to lower the cost and increase the accuracy of legal advice. See also Section III(A) (on the relative accessibility of rules and standards).

150. There also will be uncertainties concerning the application of rules that may be resolved through precedent-most notably involving boundary disputes-in which some condition determines which of two conflicting rules governs. As emphasized in the Intro- 
offers further remarks on precedent and on other factors influencing how well a law's application can be predicted. ${ }^{151}$

1. The Time Taken to Promulgate Precedents. ${ }^{152}$ As emphasized in Section I(C), the comparison of rules and standards in the case when standards become rules through precedent depends importantly on how many acts take place before the precedent is established, because individuals committing such acts will not be guided by the not-yet-established precedent. ${ }^{153}$ Presumably, the longer the time, the more such acts there will be. In our legal system, this time period often is substantial. Time passes from when actions are taken to when lawsuits are adjudicated. Lawsuits often take years to reach a conclusion and usually settle beforehand. Many levels of appeal may have to be exhausted. Finally, courts often hesitate to make clear rulings that will cover a wide range of future cases ${ }^{154}$ Instead, they may avoid a ruling on jurisdictional or other grounds, make a narrow ruling, ${ }^{155}$ state alternative grounds, fail to produce a clear majority opinion, or, with the

duction, rules are to some extent standard-like, and the difference is a matter of degree.

151. See also supra Section III(A) (on the relative accessibility of rules and standards); note 149 (on the predictability of adjudicators).

152. Precedent is usually discussed in the context of judicial decisionmaking, but the problem is similar for adjudication by administrative agencies. Agencies, however, have the additional tool of rulemaking. For a criticism of agencies' failure to promulgate rules, see FRIENDLY, supra note 9.

153. The discussion to follow usually takes precedent to be an all-or-nothing matter, as was done in Section $I(C)$. The analysis applies directly to precedents that are incomplete-in covering only some behavior subject to the standard or in providing only partial guidance with respect to the behavior covered.

154. Some of these points are emphasized $\rightarrow$ Ehrlich \& Posner, supra note 1, at 264.

155. The adoption of a multi-factor balancing test is broad to the extent it will apply to a category of cases but narrow in that each decision under the test-even if by the highest court in a jurisdiction-has little precedential value (assuming, as is usually the case, that the court refrains from stating the weight given to the factors). See, e.g., Edward Yorio, Federal Income Tax Rulemaking: An Economic Approach, 51 FoRD. L. REV. 1, 19-23 (1982). 
Supreme Court, decline to grant certiorari. ${ }^{156}$ Likewise, the scope for declaratory judgments tends to be narrow. ${ }^{157}$

As with the discussion of institutions in Section A, most of these features reflect choices rather than inherent features of a legal system. ${ }^{158}$ The current choices often involve minimizing or postponing the establishment of precedents that will guide future activity. ${ }^{159}$ The analysis here suggests that this involves a high cost, as behavior in the interim will not benefit from the guidance of whatever precedent might later be set. Also, in the interim additional costs will be incurred, both by the many who contemplate acts (in acquiring expensive, although only marginally helpful, advice) and in the many adversarial adjudications that arise, in which both parties and the court will expend resources determining how to give content to the standard.

To make the problem of delay in issuing precedent concrete, consider the following example, which considers only the cost of lawsuits (thus understating the benefit of an early determination). In the years before an issue is resolved by the creation of precedent, suppose there will be 1,000 adjudications concerning the contested issue that cost an average of $\$ 50,000$ each-a total cost of $\$ 50,000,000$. Is it likely that the later resolution will be better in some respect than an earlier determination by such an amount? ${ }^{160}$

156. For competing views on the virtue of delay in granting certiorari, see SAMUEL ESTREICHER \& JOHN SEXTON, REDEFINING THE SUPREME COURT'S ROLE: A THEORY of MANAging tHe Federal Judicial Process 48, 50-52 (1986) (favoring percolation);

$\rightarrow$ Daniel J. Meador, A Challenge to Judicial Architecture: Modifying the Regional Design of the U.S. Courts of Appeals, 56 U. CHI. L. REV. 603, 633-34 (1989) (favoring prompt resolution of conflicts involving statutory interpretation).

When there are multiple jurisdictions (as with the many circuits in the federal system), there may arise conflicting precedents. Moreover, even after consistent precedents have emerged in a number of circuits, there will remain some uncertainty as to the others and, concomitantly, the possibility that the Supreme Court will grant certiorari in a subsequent case and reverse the circuit court precedents.

157. Article III limitations affect the availability of declaratory judgments and, through other doctrines, may increase the time before a precedent is established. These restrictive doctrines have often been criticized. See, e.g., Evan T. Lee, Deconstitutionalizing Justiciability: The Example of Mootness, 105 HARV. L. REV. 603 (1992).

158. For example, some states and other countries allow the legislature to present constitutional questions to the highest court for an advance determination.

159. Not all participants in the system agree with such an approach. See, e.g., Antonin Scalia, The Rule of Law as a Law of Rules, 56 U. CHI. L. REV. 1175, 1178-80 (1989); cf. DAVIS, supra note 1, at 109 (administrators often progress from discretion toward rules at a rate behind what their current understanding makes feasible).

160. It is commonly believed that waiting has its benefits, as the experience of prior 
Might the resolution be even more satisfactory if a nontrivial portion of the $\$ 50,000,000$ were spent in reaching a careful, but prompt resolution of the point? ${ }^{161}$

This example suggests that much of our legal system may be deficient in two respects. First, massive costs of delay in settling the law are regularly incurred. Second, costs devoted to resolving an issue are not channeled in a manner designed to produce the most informed possible result. Rather, there tends to be substantial duplication, with limited guidance to actors concerning their behavior in the interim.

2. Predictability Without Precedent. A related concern is with predictability short of precedent. Prior cases-both their outcomes and any written opinions-may reduce the costs and increase the accuracy of legal advice and adjudication even if no "binding precedent" is created. ${ }^{162}$ The extent of such effects will depend on the manner in which the information produced by prior cases is made accessible. General verdicts by juries and rulings from the bench without opinion will provide limited guidance. ${ }^{163}$

cases will provide the basis for giving content to standards. See, e.g., DAVIS, supra note 1, at 107-08; Oliver W. Holmes, JR., THE COMMON LAW 111-12 $(188 \rightarrow$ Ehrlich \& Posner, supra note 1 , at 266 ; supra note 156 . The text does not question this assumption, the validity of which depends on the extent to which prior adjudications create a base of experience. (Many suits will not, as they will be settled, after significant expenditures on litigation; others will produce general verdicts but no written opinion. Also, the base of experience created may be biased. See Gillian K. Hadfield, Bias in the Evolution of Legal Rules, 80 GEO. L.J. 583 (1992).) Rather, the text asks whether waiting long periods of time so as to observe the particular cases that arise is the most sensible way to collect information, given that actions in the interim are left without more concrete and less costly guidance. (Other ways to collect information include studying actual or contemplated behavior that has not given rise to a lawsuit and been litigated to a final judgment. If one wanted experience, for example, with train accidents, existing data may be little enhanced by one court record of an adjudicated case, or even a half dozen, some years in the future. See also supra notes 63,68 .)

161. One could think of how many amicus briefs could be commissioned and examined and how many studies could be performed for even a small fraction of such an amount.

162. Cf. SCHAUER, supra note 1, at 174-81 (existence of a common law method of decisionmaking in which rules have no force in themselves but prior decisions provide guidance); id. at 182-83 (distinguishing precedent and learning from experience); see also Richard A. Posner, An Economic Approach to Legal Procedure and Judicial Administration, 2 J. LEGAL STUD. 399, 450 (1973) (suggesting that precedents involving "the compact and pointed statement communicated by [a] rule" may communicate accumulated experience to adjudicators more effectively than leaving them to extract prior experience on their own).

163. Litigators, however, will learn something from such a process. Of course, even a 
This, too, reflects a choice in designing the system. Jurors could be asked to offer opinions or identify salient factors. Judges, especially as they develop experience, could make informative pronouncements. ${ }^{164}$

3. Predictability Without Formally Articulated Rules. The predictability of a law is determined by more than formal enactments, precedents, and even the results of past adjudications. As discussed in Section III(A), individuals' common knowledge will allow confident prediction in some contexts, even when precise official pronouncements are not consulted or do not exist.

Moreover, government action outside the formal lawmaking processes can provide important guidance for future behavior. For example, the government's undertaking and publishing the results of comprehensive studies of the hazards posed by various chemicals may have a substantial effect on their use even if the results are not embodied in a regulation or formally binding in a negligence suit or other legal proceeding. ${ }^{165}$ If a regulatory agency undertook such an investigation, individuals might expect the agency to act on the results in setting its enforcement priorities and in adjudicating cases even if no rule was promulgated declaring the results to be binding. ${ }^{166}$ Undertaking such efforts is rule-like in the sense used in this Article, because such efforts are an important aspect of giving content to the law in advance of individuals' actions. ${ }^{167}$ Contrast this with a standard-like approach, in which the agency does not investigate the dangers posed by chemicals

very experienced litigator in most fields of law may have tried only a handful of cases to verdict, and the number of other relevant variables that may have affected the outcome in such cases will be relatively great. Exchanging stories, more formal conferences, and publications (by individual litigators and commercial services) all allow information to be pooled to a greater extent, although many of the factors that may have influenced a verdict will be lost in the process.

164. In some respects, the federal criminal sentencing guidelines reflect such an approach, although the guidelines are binding. The rules (with some standard-like aspects) are based in part on the prior experience of sentencing judges. See UNITED STATES SENTENCING COMMISSION, Guidelines MANUAL 1.2-1.4 (Nov. 1990).

165. See, e.g., FED. R. EVID. 803(8) (hearsay consisting of public reports admissible); FRIENDLY, supra note 9, at 144-46 (advocating that agencies present data and make policy statements).

166. An agency may choose not to make the results binding so that it can also consider subsequent information. Nonetheless, substantial predictability would be possible, in contrast to the case in which no such comprehensive study had been undertaken.

167. See supra Section I(E). 
until adjudicating the legality of a particular incident in which chemicals were discharged into a river. When a study is completed and published in advance, individuals may use it to guide their behavior and the agency may simply refer to it in an adjudication. When such a study is only to be made after-the-fact, individuals contemplating discharges of such chemicals would have to make their own investigations or act without knowledge of the actual dangers, and the agency would have to make an inquiry in each adjudication.

\section{Changing Rules and Standards over Time}

As available information, conditions, and perceived values change over time, so does the desired content of the law. In the present legal system, it is usually believed that standards are easier to keep up-to-date. ${ }^{168}$ The reason is that standards are given content in a definitive way only when they are applied to particular conduct. Thus, a standard promulgated decades ago can be applied to conduct in the recent past using present understandings rather than those from an earlier era. In contrast, rules must be changed, which may require more effort.

The importance of changes in the law as well as the ease of change will vary greatly among fields. For example, it may be quite important to be able to change income tax rules quickly (as when there is a recession), and such laws are changed, often massively, with alarming frequency. In contrast, standards of due care or determinations of causation will reflect old understandings if rules governing expert testimony exclude new theories. ${ }^{169}$

Moreover, as with other institutional features, the ease of change is a matter of choice. Standards can be applied using either present or past understandings. (Note, for example, debates on questions of interpretation about the relevance of the original intent of the framers of the Constitution or of statutes.) For rules, the manner of evolution is also chosen. Legislatures were inten-

168. See, e.g., POSNER, supra note 9, § 20.3, at 543; see also SCHAUER, supra note 1, at $140-42$ (use of rules involves trade-off between enhancing the ability of individuals to rely and preserving the ability to adapt to a changing future); cf. Hirsch, supra note 11 , at $1240-41$ (identifying changing conditions as an element limiting the benefit of precise advance specification).

169. Book Nc $\rightarrow$ Rebel Without a Cause, 105 HARV. L. REv. 935, 937-38 (1992) (reviewing PETER W. HUber, Galileo's Revenge: JUNK SCIENCE IN THE COURTROOM (1991)). 
tionally devised to make changing laws difficult (absent rather broad agreement on the need for change). But within this institutional structure, a legislature can delegate rulemaking authority to an agency, so that rules may be changed more readily. ${ }^{170}$ Also, some revision of rules is undertaken by courts, ${ }^{171}$ and this practice could be much broader if it were thought desirable. ${ }^{172}$ Precedents interpreting rules or giving content to standards can be respected more or less. ${ }^{173}$ Changes in rules or the typical application of standards can be made prospective or retroactive to varying degrees. ${ }^{174}$

How readily laws may change or evolve will affect their predictability and, relatedly, the costs incurred when seeking legal advice or when adjudicators apply the law. The more room there is for argument about changed conditions, the more such argument will be offered, at greater cost and with less certainty in guiding behavior. ${ }^{175}$ To the extent the actual legal system makes one formulation more subject to change than another, this difference will be relevant in choosing the optimal formulation.

170. See, e.g., FRIENDLY, supra note 9, at 7; HART \& SACKS, supra note 1, at 140; Erik H. Corwin, Congressional Limits on Agency Discretion: A Case Study of the Hazardous and Solid Waste Amendments of 1984, 29 HARV. J. ON LEGIS. 517, 521-22 (1992).

171. See, e.g., Guido CAlabresi, A COMMON LAW FOR THE AgE OF STATUTES (1982); POSNER, supra note 1 , at 46-47.

172. See CALABRESI, supra note 171 .

173. For an empirical assessment of the degree to which reliance on prior decisions declines with the passage of time, $: \rightarrow$ William M. Landes \& Richard A. Posner, Legal Precedent: A Theoretical and Empirical Analysis, 19 J.L. \& ECON. 249 (1976). It is familiar that an outmoded precedent may not be discarded for substantial periods of time, sometimes motivated by a desire to defer to the legislature or an administrative agency. If such issues were initially covered by a regularly reviewed statutory scheme or set of regulations, outmoded approaches may be discarded more quickly.

174. See gener $\rightarrow$ Richard H. Fallon \& Daniel J. Meltzer, New Law, Non-Retroactivity, and Constitutional Remedies, 104 HARV. L. REV. $1731(19 S \rightarrow$ Louis Kaplow, An Economic Analysis of Legal Transitions, 99 HARV. L. REV. 509 (1986).

175. The discussion in the text should not be interpreted to suggest that such uncertainty is necessarily undesirable. To the extent uncertainty concerning application of the law reflects genuine uncertainty about the appropriate content of the law, the mixed signals provided by the legal system may constitute the appropriate guide for behavior. $\rightrightarrows$ Kaplow, supra note 174 , at $533-36$ (noting the similarity between uncertainties deriving from the market and those due to government actions). There is more reason to doubt whether repeated expenditures at the enforcement stage on disputes over whether conditions have changed are justified by the social benefit of fine-tuning the law to current conditions. 


\section{Laws Regarding Form and Background Laws}

This Article focuses on legal commands regulating harmproducing behavior. Although many points would continue to be relevant, a different analysis may be required for laws regarding form (for example, a requirement that there be two witnesses to the execution of a will for it to have legal effect) ${ }^{176}$ and background laws (for example, that contract breach gives rise to liability for expectation damages, unless the contract stipulates to the contrary). Often, both types of laws are designed to facilitate rather than regulate behavior. Thus, what is best for the actors is deemed to be best for society. ${ }^{177}$

An important feature of laws regarding form is that they be cheaply accessible and precisely predictable. ${ }^{178}$ If it were left to an adjudicator ex post to determine how many witnesses give one confidence in a document, the effect may simply be to induce actors to expend excessive resources on additional witnesses, because the cost of nullification is so great. On the other hand, because laws of form are often designed to prevent fraud ${ }^{179}$ which may be easier to commit if there are known rigid rules that a fraudulent actor can carefully circumvent, standards may be preferable in some contexts. ${ }^{180}$ Such issues suggest that an appropriate

176. Some commentators have in fact distinguished the analysis of formality. See, e.g., HART, supra note 1 , at $130-\rightarrow$ Ehrlich \& Posner, supra note 1 , at 269-70; Kennedy, supra note 1 , at 1697-701. For an extended discussion of rules versus standards in a context involving contract formalities, $: \rightarrow$ Douglas G. Baird \& Robert Weisberg, Rules, Standards, and the Battle of the Forms: A Reassessment of $\S 2-207,68$ VA. L. REV. 1217 (1982).

177. For contracts, it may simply be that there are no externalities. For wills or other gratuitous transfers, other parties will be affected, but a judgment may be made that it is best to allow donors to govern their own affairs. $\rightarrow$ Steven Shavell, An Economic Analysis of Altruism and Deferred Gifts, 20 J. LEGAL STUD. 401 (1991) (arguing that donors should be able to bind themselves to give gifts).

178. The relative accessibility of rules and standards is discussed in subsection $I(A)(2)$ and Section III(A).

179. Familiar examples include the statute of frauds and parol evidence rule in contract law. See generally 3 SAMUEL Williston, A TREATISE ON THE LAW OF CONTRACTS $\S 448$ (statute of frauds); 4 id. $\S 631$ (parol evidence).

180. For example, there are general prohibitions on fraud in contract law, and the federal income tax has quite open-ended standards (in addition to more particular rules) concerning sham transactions. See, e.g., POSNER, supra note 1, at 56-60 (raising question of whether more detailed legislation and regulation or more ex post plugging of loopholes by courts is better course for federal taxation); supra note 125 (that rules are more predictable implies that errors in the law will be more predictable). Consider a complex standard that prohibits types of fraud or circumvention of parties' or legislatures' intent. 
framework, taking into account effects on legitimate and fraudulent behavior, would differ from the one presented here. Yet, some factors will be the same. Most important is that laws of form often regulate extremely numerous acts and transactions, so the cost savings from ex ante creation of the law (rules) will be particularly significant.

Background laws raise different issues, and therefore would require that yet another framework be created. For example, an open-ended standard providing that ambiguity and incompleteness in contracts will be supplemented by courts ex post in the manner parties would have agreed to had they provided for the contingency has desirable properties. When parties contemplate entering into a contractual relationship, they have only a limited need to know how a court would fill gaps in their agreement, ${ }^{181}$ as long as the court (or another designated decisionmaker) could be anticipated to act as they would wish. ${ }^{182}$ The primary reason parties leave much unspecified is precisely to avoid the costs of specification. This cost savings would be nullified (or exceeded) if they invested in legal advice to inform themselves about how a court would provide for unspecified events. Thus, the calculus determining whether rules or standards are preferable would emphasize ex

Applying such a law in enforcement proceedings may often be costly. But if actors anticipated that such a law would be applied well (and if they knew rather well which acts were fraudulent or circumventions), they might be deterred from such activity. Then enforcement costs may not be incurred very often and costs of legal advice also may be modest if lawyers could predict with reasonable confidence that questionable schemes simply were not worth the bother. The problem is that, if it is not sufficiently clear ex ante or ex post which schemes are indeed improper, those engaged in possibly legitimate behavior may incur substantial legal costs to verify that their conduct is permissible or simply be deterred from committing desirable activity. Similarly, legitimate schemes may often be challenged in enforcement proceedings using such standards.

181. To determine what price is acceptable, they will care about the expected value of the contract, which will depend on how each contingency would be addressed. But a reasonably good approximation may be possible without a prediction of how each contingency would be resolved. If one party is more informed of the background rules, perhaps because it is sensible to be more knowledgeable when one enters into such transactions repeatedly, that party might have an advantage, which in turn may affect what the other party is willing to offer or may induce the other party to acquire additional advice to determine whether there might exist important background rules that would operate to its disadvantage.

182. See David Charny, Hypothetical Bargains: The Normative Structure of Contract Interpretation, 89 MICH. L. REV. 1815, 1819-23 (19s $\rightarrow$ David Charny, Nonlegal Sanctions in Commercial Relationships, 104 HARV. L. REV. 373, $444(199 \rightarrow$ Steven Shavell, Damage Measures for Breach of Contract, 11 BELL J. ECON. 466, 466-69 (1980). 
ante promulgation costs and ex post enforcement costs, giving less attention to costs of advice by contracting parties because they often would not choose to acquire advice about such matters. ${ }^{183}$

\section{E. Lawyers' Interest in How the Law Is Formulated}

The legal profession is not indifferent to how laws are designed. Since some of the promulgation costs and much of the costs of advice and enforcement consist of fees for lawyers' services, the profession as a whole has a general interest that tends to oppose that of society. Laws that induce individuals to seek advice more frequently or to seek advice having a higher cost, ${ }^{184}$ or that increase the cost of litigation, will be favorable to the economic interest of lawyers. ${ }^{185}$ Thus, while the bar will often have special expertise in evaluating many of the factors relevant to the design of laws, one must keep in mind that lawyers' advice on such matters may be tinged by self-interest. ${ }^{186}$

183. If they had reason to believe that their preferences were atypical, and thus would not be reflected in the rules or in an adjudicator's application of the standard, they would want to include special provisions. But some advice may be necessary to have a sense of whether one's situation is likely to be atypical. Sometimes, however, it might be cheapest simply to include such provisions in the contract without incurring the cost to determine whether they are necessary. Thus, many contracts contain extensive boilerplate providing for the result an adjudicator would likely reach in any event.

184. These factors oppose each other to some extent, because higher costs of advice tend to decrease the demand for it. It remains true, however, that there is a divergence of interests, because laws that maximize expenditures on legal advice are unlikely to be those that are socially best (particularly as expenditures on legal advice are a social cost, though a private benefit to the profession).

185. See, $e \rightarrow$ Ehrlich \& Posner, supra note 1, at 271, 274 (emphasizing that lawyers may prefer judge-made law because precedents, which state rules implicitly, require more legal skill to master than statutes). See generally Michelle J. White, Legal Complexity and Lawyers' Benefit from Litigation, 12 INT'L REV. L. \& ECON. 381 (1992).

186. Any individual lawyer would have little interest in the formulation (unless there is extreme specialization), but lawyers often act as a group through professional associations. Lawyers may also have different interests depending on their past investments in learning rule systems or in predicting standards. See supra notes 40,163. Finally, it is unethical for a lawyer (not representing a client) to advocate reforms in the profession's self-interest that are not believed to be in the public interest, see MODEL CODE OF PROFESSIONAL RESPONSIBILITY EC 8-4 (1980); MODEL RULES OF PROFESSIONAL CONDUCT Rule 6.4 (1989); however, lawyers' perceptions of the public interest may be influenced by their self-interest and the effect of ethical guidelines on such behavior is speculative in any event. 


\section{CONCLUSION}

This Article provides an economic analysis of rules and standards, focusing on the extent to which the law should be given content before individuals act (rules), rather than waiting until afterward (standards). The problem motivating the choice is that giving appropriate content to the law often requires effort, whether in analyzing a problem, resolving value conflicts, or acquiring empirical knowledge. Undertaking such effort in advance involves additional costs, but results in savings when individuals must determine how the law applies to their contemplated conduct and when adjudicators must apply the law to past conduct.

The central factor influencing the desirability of rules and standards is the frequency with which a law will govern conduct. $^{187}$ If conduct will be frequent, the additional costs of designing rules-which are borne once-are likely to be exceeded by the savings realized each time the rule is applied. Thus, rules involve a wholesale approach to an information problem, that of determining the law's appropriate content. ${ }^{188}$ Standards instead require adjudicators to undertake this effort, which may have to be done repeatedly (unless the standard is transformed into a rule through precedent $^{189}$ ). And, regardless of whether adjudication will be frequent, many individuals contemplating behavior that may be subject to the law will find it more costly to comply with standards, because it generally is more difficult to predict the outcome of a future inquiry (by the adjudicator, into the law's content) than to examine the result of a past inquiry.$^{190}$ They must either spend more to be guided properly or act without as much guidance as under rules. Thus, when behavior subject to the relevant law is frequent, standards tend to be more costly and result in behavior that conforms less well to underlying norms.

If behavior subject to the law is infrequent, however, standards are likely to be preferable. Of particular relevance are laws for which behavior varies greatly, so that most relevant scenarios are unlikely ever to occur. Determining the appropriate content of the law for all such contingencies would be expensive, and most of

187. See supra Sections I(B), III(B).

188. See supra Section I(E).

189. See supra Section $\mathrm{I}(\mathrm{C})$; subsection IV(B)(1).

190. On the possibility that standards can be more accessible to individuals, see Section III(A). 
the expense would be wasted. It would be preferable to wait until particular circumstances arise.

Some implications of this analysis run contrary to prevailing wisdom or suggest problems with common practices. Thus, it is usually said that standards result in more precise application of underlying norms because they can be applied to the particular facts of a case, in contrast to rules, which apply to the generality of cases. But if the cases are anticipated to arise frequently and have important recurring characteristics, rules will not only be preferable, but might be expected to be more precise. ${ }^{191}$ In such instances, it is worth investing substantial effort to fine-tune a rule system. But, with standards, it may not be worth spending much effort to get precise results, because such efforts will be useful in resolving only a single case rather than many. Moreover, even in instances where standards would produce more accurate results in adjudication, rules may nevertheless produce behavior more in accord with underlying norms. The reason is simply that the rules, announced in advance, are more likely to influence actual behavior, whereas individuals may find it infeasible or too costly to predict how an adjudicator will apply a standard to their behavior. The discussion noted OSHA regulations and the tax code and regulations as examples of rule schemes likely to be far more precise in their application than the results one would expect to be produced by juries operating under a general standard. ${ }^{192}$

The analysis also is relevant to the processes by which laws are given content, including through precedent. ${ }^{193}$ When a law will govern much behavior, there are substantial benefits to an early determination of its content. When legislators leave the details of law to courts (or to agencies that do not promptly issue regulations ${ }^{144}$ ), individuals may be left with little guidance for years or decades, while substantial legal costs are incurred both in providing advice to actors and in adjudicating disputes over unresolved questions. Similar costs are imposed when courts delay in promulgating precedents-whether by avoiding a decision or decid-

191. See supra subsection I(D)(3); Section II(D).

192. To be sure, individual jury verdicts under such a standard would be more varied due to inconsistencies. See supra Section II(A). But it is unlikely that any jury would go into such detail with respect to the factors giving rise to the content of these rule schemes.

193. See supra Section I(C); subsection IV(B)(1).

194. See FRIENDLY, supra note 9. 
ing narrowly. Delay to a more convenient time, perhaps when there will be more experience, is considered a virtue. Whether the benefits are warranted by the interim legal costs receives little attention; costs involving individuals' attempts to comply with the law, in contrast to costs of adjudicated cases, receive even less. Moreover, when the law is finally given content, even in precedent-setting cases in the Supreme Court, the investment in reaching a correct decision is rarely in proportion to the magnitude of the stakes. And the investment is usually a trivial fraction of the total costs incurred in previous duplicative disputes over the same issue.

While the legal system, including the courts, is generally understood as a producer of law, basic considerations of efficient production-here, of an information product ${ }^{195}$-are foreign to most commentary on rules and standards. ${ }^{196}$ Legal costs and the extent to which individuals will conform their behavior to the law are, to be sure, not the only relevant factors in choosing between rules and standards. They are, however, more significant than may first appear, because many of the institutional considerations usually thought to bear on the choice can be, and sometimes are, addressed separately from whether efforts to give content to the law are undertaken before or after individuals act.

195. See supra Section I(E).

196. It would be useful to compare the manner in which the laws of states are produced to that in which large corporations produce their own rules and standards for internal operations. While there are many important differences, the similarities are sufficiently great that the comparison should not be ignored. 


\section{APPENDIX}

This Appendix formally presents an example of the kind analyzed in Part I. No attempt is made here to repeat the motivation, interpretation, or numerous caveats that appear in the body of the Article. For completeness, the presentation includes the case in which the first adjudication creates a precedent for subsequent enforcement proceedings, as described in Section I(C). In addition, the particular law that is chosen (strict liability, with damages equal to harm caused) is one for which the private and social values of legal advice are equal. (See the discussion in Section III(C).)

\section{The Example}

The government enacts a law subjecting a harm-causing activity to strict tort liability. Initially, the government does not know the level of harm $h$ caused by this activity; it is believed that harm is distributed according to the density $f(\cdot)$ on $[0, \infty)$. It may promulgate a standard, which simply means that courts will determine $h$ when individuals are sued. Or, it may promulgate a rule, which states the level of damages a court will award. In order to promulgate a rule, the government must first undertake an investigation, which determines the actual $h \cdot{ }^{197}$ The cost of promulgating the law is $k_{i}$, where $i=r, s$ (denoting "rule" and "standard"); $k_{r}>k_{s}$. Let $k=k_{r}-k_{s}$.

There are $n$ identical risk-neutral individuals who engage in an activity that causes harm $h$ with probability $p$. Individuals decide how much care to exercise; expenditures on care $x$ reduce the probability of harm at a diminishing rate: $p^{\prime}(x)<0, p^{\prime \prime}(x)>0$. Individuals do not know the level of damages a court will award; they know only the distribution $f(\cdot)$. Before choosing their level of care, they may obtain advice, which tells them what a court will award, at a cost of $c_{i}$, where $i=r, s ; c_{s}>c_{r}$; and $c=c_{s}-c_{r}$. Individuals decide whether to acquire information and choose a level of care to minimize the sum of their cost of care, their expected liability costs, and the cost of information.

197. The example is more general than may first appear. Consider, for example, the possibility that $h$ has two possible values, one of which is zero. Then, the inquiry is equivalent to determining which acts are harmful and thus subject to legal sanctions. 
Individuals who cause harm pay damages equal to the actual value of $h$. The cost of an enforcement proceeding is $e_{i}$, where $i=r, s ; e_{s}>e_{r} ;$ and $e=e_{s}-e_{r}$.

Finally, when there is a standard, the analysis will consider two possibilities concerning the first court determination of the actual level of $h$. First, it might be a precedent for future enforcement actions, in which event the situation thereafter will be as though a rule rather than a standard prevails. (That is, enforcement costs in the future will be $e_{r}$ and future costs of information will be $c_{r}{ }^{198}$ ) Second, it may not be a precedent, in which event the standard prevails indefinitely.

The social objective is the minimization of the sum of the cost of care, expected harm, and all legal costs-the costs of promulgating the law, individuals' expenditures to learn $h$, and the costs of enforcement proceedings.

\section{Individuals' Behavior}

If individuals act without becoming informed of the actual $h$ (and thus the amount of damages a court will award), they will choose a level of care $x_{u}$ ("u" for "uninformed") to minimize the sum of the cost of care and expected damage payments, so their expected total cost will be

$$
\text { (1) } C_{u}=x_{u}+p\left(x_{u}\right) \int_{0}^{\infty} h f(h) d h \text {. }
$$

If they first acquire advice, they will learn the actual $h$ and choose the level of care $x_{i}(h)$ ("i" for "informed") to minimize the sum of the cost of care and expected damage payments, and their expected total cost will be

$$
\text { (2) } C_{i}=\int_{0}^{\infty}\left[x_{i}(h)+p\left(x_{i}(h)\right) h\right] f(h) d h \text {. }
$$

Observe that the expressions for $C_{u}$ and $C_{i}$ measure both the private and social costs (aside from enforcement costs ${ }^{199}$ ) in each case for the familiar reason that strict liability requires individuals

198. It would be straightforward to consider the situation in which the precedential effect lowered subsequent enforcement costs but not individuals' information costs, or the converse, or that in which enforcement or information costs were reduced but not completely to the level under a rule. See, e.g., infra note 204.

199. See supra note 117. 
to pay damages for all harm caused, and because, in this model, actual court awards will equal actual harm under both a rule and a standard. Thus, both the expected private and expected social values of information are given by the same expression:

(3) $I=C_{u}-C_{i}$.

It is apparent that $I$ must be positive, because informed individuals are able to choose their level of care with knowledge of $h^{200}$

Individuals will choose to become informed whenever $I>c_{i \cdot}{ }^{201}$ Thus, there are three cases to consider: $I \leq c_{r}<c_{s}$; $c_{r}<c_{s}<I$; and $c_{r}<I \leq c_{s}$. In the first case, individuals do not become informed regardless of the formulation of the law; in the second, they become informed regardless of the formulation; and, in the third, they become informed if there is a rule but not if there is a standard.

Case 1: Individuals Do Not Become Informed Either Under a Rule or Under a Standard. Because uninformed individuals do not incur the costs $c_{i}$ and take the same level of care $x_{u}$ regardless of whether a rule or standard prevails, the only considerations pertinent to the relative efficiency of rules versus standards are promulgation costs $k_{i}$ and enforcement costs $e_{i}$.

Precedent. If there will be at least one enforcement proceeding, a rule will be more expensive than a standard if and only if

(4) $\mathrm{k}>\mathrm{e}$.

That is, rules are more expensive when the cost of determining the actual $h$ at the promulgation stage exceeds that of determining the actual $h$ at the enforcement stage. To the extent that there is a significant probability that there would never be an enforcement proceeding under a standard, however, a standard would likely be less expensive. ${ }^{202}$

200. It is straightforward to show (from the first-order conditions when (1) and (2) are minimized with respect to the choice of $x$ ) that informed individuals choose a different level of care whenever $h$ does not equal the mean of $h$-more (less) care when $h$ is greater (less) than the mean of $h$.

201. Choice in cases of indifference are stipulated for convenience, without affecting the analysis. It is implicitly assumed that individuals either know whether a rule or standard prevails or that finding out the type of formulation is costless.

202. There will be at least one proceeding with probability $1-\left(1-p\left(x_{w}\right)\right)^{n}$, which will 
No precedent. The expected cost of a rule will exceed that for a standard if and only if

(5) $k>n p\left(x_{u}\right) e$.

Using as a baseline the case in which $k=e$, the inequality (5) will hold when the expected number of suits, $n p\left(x_{u}\right)$, is less than one.

\section{Case 2: Individuals Become Informed both Under a Rule and} Under a Standard. Because informed individuals take the same level of care, $x_{i}(h)$, regardless of whether a rule or standard prevails, the considerations pertinent to the relative efficiency of rules versus standards are promulgation costs $k_{i}$, information costs $c_{i}$, and enforcement costs $e_{i}$.

Precedent. If there will be at least one enforcement proceeding, a rule will be more expensive than a standard if and only if

$k>A c+e$

where $A$ is the expected number of individuals who act before the first enforcement proceeding. ${ }^{203}$ Using as a baseline the case in which $k=e$, a standard will be more expensive than a rule by the amount $A c .^{204}$ Observe that if there is never an enforcement proceeding, the standard saves the promulgation cost differential $k$, but it still may be more expensive because the information cost differential $c$ will then be incurred $n$ times.

No precedent. The expected cost of a rule will exceed that for a standard if and only if

(7) $k>n c+n \bar{p} e$,

where $\bar{p}$ denotes the expected probability of accidents when individuals are informed. (Recall that $x_{i}$ is a function of $h$; hence, $\bar{p}$ is

almost equal 1 if $n$ is sufficiently large.

203. Obviously, $A$ is greater than or equal to one. The value of $A$ will depend on the actual $h$, because the probability of harm depends on $h$ when individuals are informed. When $p\left(x_{i}(h)\right)$ is very small, $A$ will be large and the cost differential noted in the text will be substantial.

204. If, after a precedent, there was still some additional information cost under a standard-because a precedent was more expensive to identify than a rule-there would be an added component of $n$ - $n$ times this differential. 
the expectation of $p\left(x_{i}(h)\right)$ over $h$.) Using as a baseline the case in which $k=e$, a necessary condition for (7) to hold is that the expected number of suits, $n \bar{p}$, is less than one. This is not sufficient, because any cost advantage of a standard would have to exceed $n c$, which can be very large even when $n \bar{p}$ is small. A rule can be more expensive than a standard only if the additional promulgation costs exceed each individual's information cost savings by a factor exceeding $n$.

Case 3: Individuals Become Informed Under a Rule but Not Under a Standard. This case differs from the first two because behavior is no longer the same under a rule and a standard. Under a rule, individuals spend $c_{r}$ and choose the level of care $x_{i}(h)$. Under a standard, individuals make no expenditure on information and choose the level of care $x_{u}$, which in general results in a different probability of harm than when individuals are informed. The difference in effect on social welfare for each individual is simply $I-c_{r}$, because the expected social value of information (abstracting from enforcement costs) equals $I$. This captures both the difference in the level of expected harm and the difference in the level of care. Moreover, in case 3, it must be that $I>c_{r}$, so the effect on social welfare of each individual's behavior under a rule, including the information acquisition cost, is more desirable than under a standard.

Precedent. If there will be at least one enforcement proceeding, a rule will be more expensive than a standard if and only if

(8) $\mathrm{k}>\mathrm{A}\left(\mathrm{I}-\mathrm{c}_{\mathrm{r}}\right)+\mathrm{e}$.

Expression (8) is the same as expression (4) (for case 1, precedent) except that the term $n\left(I-c_{r}\right)$, which is positive, appears on the right. Thus, when the benefit of information is sufficiently great that individuals acquire information under a rule (but not under a standard), the relative desirability of a rule is greater than when they do not. It is also useful to compare expression (8) with expression (6). The difference is that, with regard to the stage involving individual behavior, the benefit of rules in case 3 involves the improvement in behavior net of information costs, while in case 2 it involves the relative cost savings in becoming informed about rules rather than standards. 
No precedent. The expected cost of a rule will exceed that for a standard if and only if

$$
\text { (9) } k>n\left(I-c_{r}\right)+n\left(p\left(x_{u}\right) e_{s}-\bar{p} e_{r}\right) \text {. }
$$

The left side of (9) is the additional promulgation cost of a rule. The first component on the right side is the net benefit concerning behavior (the behavioral benefit $I$ minus the cost of information $c_{r}$ ) for all individuals who act. The second component is the net enforcement cost difference, which is formally ambiguous because the relative magnitudes of $p\left(x_{u}\right)$ and $\bar{p}$ cannot be determined $a$ priori. (Informed individuals take more care and thus cause harm less frequently when they learn that $h$ is above average and take less care, causing harm more often, when they learn that $h$ is below average.) If one considers the case in which these probabilities are equal, this second component favors rules in the same manner as in the prior two cases. ${ }^{205}$ 